\title{
Endogenous $\alpha$-Synuclein Is Induced by Valproic Acid through Histone Deacetylase Inhibition and Participates in Neuroprotection against Glutamate-Induced Excitotoxicity
}

\author{
Yan Leng and De-Maw Chuang \\ Molecular Neurobiology Section, Biological Psychiatry Branch, National Institute of Mental Health, National Institutes of Health, Bethesda, Maryland \\ 20892-1363
}

\begin{abstract}
Emerging evidence suggests that $\alpha$-synuclein ( $\alpha$-syn), which is traditionally thought to have a pathophysiological role in neurodegenerative diseases, can have neuroprotective effects. This study aimed to investigate whether endogenous $\alpha$-syn in neurons can be induced by valproic acid (VPA), a mood-stabilizer, anticonvulsant and histone deacetylase (HDAC) inhibitor, and if so, whether the $\alpha$-syn induction is neuroprotective. VPA treatment of rat cerebellar granule cells caused a robust dose- and time-dependent increase in levels of $\alpha$-syn protein and mRNA and in the intensity of $\alpha$-syn immunostaining. Knockdown of VPA-induced $\alpha$-syn overexpression with $\alpha$-syn antisense oligonucleotides or siRNA completely blocked VPA-induced neuroprotection. $\alpha$-Syn knockdown also exacerbated glutamate neurotoxicity, stimulated the expression of the proapoptotic gene ubiquitin-conjugating enzyme E2N, and downregulated the expression of the anti-apoptotic gene Bcl-2. Induction of $\alpha$-syn by VPA was associated with inhibition of HDAC activity, resulting in hyperacetylation of histone $\mathrm{H} 3$ in the $\alpha$-syn promoter and a marked increase in $\alpha$-syn promoter activity. Moreover, VPA-induced $\alpha$-syn induction and neuroprotection were mimicked by HDAC inhibitors sodium 4-phenylbutyrate and trichostatin A (TSA). $\alpha$-syn was also induced by VPA in rat cerebral cortical neurons. Additionally, treatment of rats with VPA, sodium butyrate, or TSA markedly increased $\alpha$-syn protein levels in the cortex and cerebellum. Together, our results demonstrate for the first time that VPA induces $\alpha$-syn in neurons through inhibition of HDAC and that this $\alpha$-syn induction is critically involved in neuroprotection against glutamate excitotoxicity. Clinically, VPA may represent a suitable treatment for excitotoxicity-related neurodegenerative diseases.
\end{abstract}

Key words: $\alpha$-synuclein; valproate; neuroprotection; excitotoxicity; histone deacetylase; Parkinson's disease

\section{Introduction}

The synuclein family of proteins are predominantly expressed in neurons and include three structurally similar isoforms termed $\alpha, \beta$, and $\gamma . \alpha$-Synuclein ( $\alpha$-syn), a presynaptic protein of poorly understood function, is associated with synaptic vesicles (Jo et al., 2000 ) and has been suggested to have a role in synapse formation and plasticity (Cabin et al., 2002; Liu et al., 2004). $\alpha$-Syn is a natively unfolded molecule that can self-aggregate to form oligomers and fibrillar structures that accumulate in brain Lewy bodies in Parkinson's disease (PD) patients (Norris et al., 2004). Additionally, mutations in three loci (A53T, A30P, and E46K) in $\alpha$-syn have been linked to the heritable form of PD (Polymero-

Received Jan. 28, 2005; revised May 2, 2006; accepted June 11, 2006.

This work was supported by the Intramural Research Program of National Institute of Mental Health (NIMH)/ National Institutes of Health (NIH). We thank Drs. Robert L. Nussbaum and Ornit Chiba-Falek (National Human Genome Institute/NIH) for their generous gift of the $1.9 \mathrm{~kb}$ DNA fragment of human $\alpha$-synuclein promoter. We thank Dr. Weihan Wang (Uniformed Services University of the Health Sciences, Bethesda, MD) for technical assistance and Peter Leeds (NIMH) and the NIH Fellows' Editorial Board for editorial assistance. We also thank Qingxiang Wei (National Institute of Child Health and Human Development/NIH) and Dr. Min-Hui Liang in our section for assistance in the real-time RT-PCR and siRNA transfection experiments, respectively.

Correspondence should be addressed to Dr. De-Maw Chuang, Molecular Neurobiology Section, National Institute of Mental Health, National Institutes of Health, Building 10, Room 4C206, 10 Center Drive, MSC 1363, Bethesda, MD 20892-1363. E-mail: chuang@mail.nih.gov.

DOI:10.1523/JNEUROSCI.0096-06.2006

Copyright $\odot 2006$ Society for Neuroscience $\quad$ 0270-6474/06/267502-11\$15.00/0 poulos et al., 1997; Krüger et al., 1998; Zarranz et al., 2004). Therefore, $\alpha$-syn is generally considered to have a neurotoxic role in the pathogenesis of PD.

However, there is a growing body of evidence suggesting that $\alpha$-syn can also have neuroprotective effects both in vitro and in vivo. For example, exogenous or overexpressed $\alpha$-syn protects against multiple insults in cultured neurons (Seo et al., 2002; Alves da Costa et al., 2000, 2002; Jensen et al., 2003). Transgenic expression of $\alpha$-syn prevents paraquat-induced degeneration of nigrostriatal dopaminergic neurons and cysteine-string protein$\alpha$-induced nerve terminal injury (Manning-Bog et al., 2003; Chandra et al., 2005). The neuroprotective mechanisms of $\alpha$-syn appear to include the activation of phosphatidylinositol 3-kinase/ Akt, suppression of p53 and c-Jun-N-terminal kinase (JNK) signaling, as well as the induction of neuroprotective/neurotrophic factors (Seo et al., 2002; Alves da Costa et al., 2002; M. Hashimoto et al., 2002; Manning-Bog et al., 2003; Albani et al., 2004; Kohno et al., 2004). Despite this information, there is no report on neuroprotection elicited by raising the endogenous levels of $\alpha$-syn pharmacologically.

Valproic acid (VPA) is a mainstay drug alternative to lithium in treating bipolar mood disorder and has been widely used as an anticonvulsant for seizure patients. Emerging evidence supports the notion that VPA has neuroprotective effects in vitro, includ- 
ing neuroprotection against glutamate excitotoxicity (R. Hashimoto et al., 2002; Kanai et al., 2004), endoplasmic reticulum stress (Bown et al., 2000; Kim et al., 2004; Hiroi et al., 2005), and lipopolysaccharide-induced microglial activation and dopaminergic neuronal death (Peng et al., 2005). In a rat cerebral ischemic model, post-insult VPA treatment suppresses ischemiainduced brain damage and neurological deficits (Ren et al., 2004). VPA neuroprotection is associated with hyperacetylation of histones (Ren et al., 2004; Kanai et al., 2004), presumably through the inhibition of histone deacetylase (HDAC), a recently identified target of VPA (Phiel et al., 2001; Göttlicher et al., 2001). An increasing number of reports suggest the potential of using HDAC inhibitors including VPA to treat acute and chronic neurological diseases such as stroke, polyglutamine-expansion diseases, amyotrophic lateral sclerosis (ALS), and Alzheimer's disease (for review, see Langley et al., 2005). The present study was undertaken to investigate whether VPA-mediated HDAC inhibition results in transcriptional upregulation of $\alpha$-syn and whether the resultant increase in endogenous levels of this protein participates in the neuroprotective effects against glutamate-induced excitotoxicity in rat brain neurons.

\section{Materials and Methods}

Primary cultures of cerebellar granule cells. Cerebellar granule cell (CGC) cultures were prepared from 8-d-old Sprague Dawley rats as described previously (Nonaka et al., 1998) with some modifications. Briefly, the dissociated cells were resuspended in serum-free B27/neurobasal medium and plated at a density of $1.2 \times 10^{6} \mathrm{cells} / \mathrm{ml}$ on $0.01 \%$ poly-L-lysine precoated plates, dishes, or glass chamber slides. Cytosine arabinofuranoside $(10 \mu \mathrm{M})$ was added to the cultures $\sim 24 \mathrm{~h}$ after plating to arrest the growth of non-neuronal cells. The cultures were routinely pretreated with indicated concentrations of VPA for 5-7 d, starting from $1 \mathrm{~d}$ in vitro (DIV), and then exposed to $100 \mu \mathrm{M}$ glutamate for $24 \mathrm{~h}$ to induce neurotoxicity. At the time of experimentation, $>92 \%$ of cells represent CGC neurons.

Cortical cell culture. Neuron-enriched cerebral cortical cells were prepared from the brains of 18-d-old Sprague Dawley rat embryos, essentially as described previously (R. Hashimoto et al., 2002). Briefly, cortices were dissected from embryonic brain and the meninges was removed. The cells were dissociated by trypsinization and trituration, followed by DNase treatment. The dissociated cells were resuspended in serum-free B27/neurobasal medium and plated at a density of $3 \times 10^{5} \mathrm{cells} / \mathrm{cm}^{2}$ on dishes precoated with poly-L-lysine. The cells were maintained at $37^{\circ} \mathrm{C}$ in the presence of $5 \% \mathrm{CO}_{2} / 95 \%$ air in a humidified incubator. After DIV 6 , cortical neurons were treated with VPA or its vehicle and maintained for $4 \mathrm{~d}$ in cultures.

Western blotting. Cultured CGCs and cortex neurons were detached by scraping and then sonicated for $30 \mathrm{~s}$ in lysis buffer as described previously (Leng et al., 2001). Aliquots containing equal amounts of protein $(15 \mu \mathrm{g})$ from each sample were dissolved in an equal volume of SDS sample buffer, loaded onto a $4-12 \%$ Nupage Bis-Tris gel, and then subjected to electrophoresis. After separation, proteins were transferred to a polyvinylidene difluoride membrane, which was incubated for $1 \mathrm{~h}$ with the primary antibody against $\alpha$-syn (1:500; BD Transduction Laboratories, San Jose, CA), acetylated histone H3 (1:3000; Upstate Biotechnology, Lake Placid, NY), $\beta$-actin (1:5000; Sigma, St. Louis, MO), phosphoeukaryotic initiation factor $2-\alpha$ (eIF $2 \alpha$ ) (1:1000; Abcam, Cambridge, MA), ubiquitin-conjugating enzyme E2n (Ube2n) (1:1000; Abcam), and Bcl-2 (1:500, Santa Cruz Biotechnology, Santa Cruz, CA), in $0.01 \%$ Tween-20/PBS and then with the HRP-labeled secondary antibody (1: 2000; Amersham Biosciences, Piscataway, NJ). The reactive bands were visualized by detecting chemiluminescence.

Total RNA extraction, reverse transcription-PCR, and semiquantitative mRNA expression. Total RNA from CGCs was obtained by using the RNeasy Mini kit (Qiagen, Valencia, CA) according to instructions of the manufacturer. Specific primers used were as follows: for rat $\alpha$-syn, $5^{\prime}$ GAAAACCAAGCAGGGTGTG-3' (forward) and 5'-CACTGCTGAT-
GGAAGACTTTG-3' (reverse); for rat Bcl-2, 5'-TGGACAACATCGCTCTGTGGATGA-3' (forward) and $5^{\prime}$-TGTGTGTGTGTGTGTGTGTTCTGC-3' (reverse); for rat Ube2n, 5' -TGTAGCTGAGCAGTGGAAGAGCAA-3' (forward) and 5'-TCTACACCTGACGGCAAAGTCACA-3' (reverse); and for rat $\beta$-actin, $5^{\prime}$-CCACAGCTGAGAGGGAAATCG-3' (forward) and 5'-AGTAACAGTCCGCCTAGAAGCA-3' (reverse). The primers were used to obtain the first cDNA strand by reverse transcription (RT) at $48^{\circ} \mathrm{C}$ for 20 min followed by denaturation for $2 \mathrm{~min}$ at $94^{\circ} \mathrm{C}$. The subsequent amplification of the cDNAs was performed using PCR: denaturation, $1 \mathrm{~min}$ at $94^{\circ} \mathrm{C}$; annealing, $1 \mathrm{~min}$ at $55^{\circ} \mathrm{C}$; and extension, $1 \mathrm{~min}$ at $68^{\circ} \mathrm{C}$ during 35 cycles with a Biometra (Göttingen, Germany) T-gradient thermoblock. The RT-PCR products were analyzed by $1.2 \%$ agarose gel electrophoresis and visualized with ethidium bromide staining.

Quantitative real-time RT-PCR. For relative quantification of mRNA levels for the genes of interest, quantitative real-time RT-PCR was performed using TaqMan universal PCR master mix (Applied Biosystems, Foster City, CA). Real-time PCR was performed from reversetranscribed cDNA samples. Briefly, $1 \mu$ g of each RNA sample was reverse transcribed into cDNA in a $100 \mu \mathrm{l}$ reaction by using High-Capacity cDNA Archive Kit (Applied Biosystems). The RT was performed at $25^{\circ} \mathrm{C}$ for $10 \mathrm{~min}$ and $37^{\circ} \mathrm{C}$ for $120 \mathrm{~min}$. An aliquot of $22.5 \mu \mathrm{l}$ of each diluted cDNA was used as a template for each PCR in conjunction with $25 \mu \mathrm{l}$ of TaqMan universal master mix and $2.5 \mu \mathrm{l}$ matched TaqMan gene expression assay mixture (Applied Biosystems) containing a $20 \times$ mix of forward primer, reverse primer, and 6-carboxyfluorescein-labeled TaqMan minor groove binder probe in a total volume of $50 \mu$ l. TaqMan gene expression assay kits for $\alpha$-syn, Bcl-2, Ube2n, $\beta$-actin were also obtained from Applied Biosystems. A negative control lacking RT enzyme was included in each assay. The PCR cycling was performed first by incubation at $50^{\circ} \mathrm{C}$ for $2 \mathrm{~min}$ followed by $95^{\circ} \mathrm{C}$ for $10 \mathrm{~min}$ and then 40 cycles of $95^{\circ} \mathrm{C}$ for $15 \mathrm{~s}$ and $60^{\circ} \mathrm{C}$ for $1 \mathrm{~min}$. The cycle threshold $\left(\mathrm{C}_{\mathrm{t}}\right)$ values corresponding to the PCR cycle number at which fluorescence emission in real time reaches a threshold above the baseline emission were determined. The fold induction or repression by real-time RT-PCR was measured in triplicate relative to matched vehicle-treated controls and calculated after adjusting for $\beta$-actin using $2^{-\Delta \Delta C t}$, where $\Delta C_{t}$ is target gene $C_{t}-\beta$-actin $\mathrm{C}_{\mathrm{t}}$, and $\Delta \Delta \mathrm{C}_{\mathrm{t}}$ is $\Delta \mathrm{C}_{\mathrm{t}}$ control $-\Delta \mathrm{C}_{\mathrm{t}}$ treatment.

Measurement of cell viability. The mitochondrial dehydrogenase activity that reduces 3-(4,5-dimethylthiazol-2-yl)-2,5-diphenyl tetrazolium bromide (MTT) was used to determine cell survival in a quantitative colorimetric assay (Nonaka et al., 1998). CGCs were incubated with MTT $(125 \mu \mathrm{g} / \mathrm{ml})$ added directly to the growth medium for $1 \mathrm{~h}$ at $37^{\circ} \mathrm{C}$. The medium was then aspirated, and the formazan product was dissolved in dimethylsulfoxide and quantified spectrophotometrically at $540 \mathrm{~nm}$. The results are expressed as a percentage of viability of the control culture.

Immunofluorescence. CGCs were cultured on poly-L-lysine precoated chamber glass slides (Nalge Nunc International, Naperville, IL). After treatment with $0.2 \mathrm{~mm}$ VPA for $6 \mathrm{~d}$ (DIV 1 to DIV 7), CGCs were washed with PBS, fixed with methanol, and then blocked with $3 \%$ goat serum for $15 \mathrm{~min}$. Cells were washed again with PBS and incubated for $1 \mathrm{~h}$ with anti- $\alpha$-syn antibody (1:50 dilution). After washing with PBS, the cells were incubated for $1 \mathrm{~h}$ with goat anti-mouse Rhodamine Red-XAffiniPure-conjugated secondary antibodies (1:50) (Jackson ImmunoResearch, West Grove, PA), washed with PBS, and mounted. Nuclei were stained with 4', 6-diamidino-2-phenylindole (DAPI) $(1.5 \mu \mathrm{g} / \mathrm{ml})$ included in the mounting medium (Vectashield; Vector Laboratories, Burlingame, CA) to yield blue fluorescent nuclear images. Fluorescent labeling was examined with a Zeiss (Oberkochen, Germany) Axiophot microscope equipped with a digital camera.

Analysis of chromatin condensation. Chromatin condensation was detected by staining of cell nuclei with Hoechst dye 33258. CGCs grown on $35 \mathrm{~mm}$ dishes were washed with ice-cold PBS and fixed with $4 \%$ formaldehyde in PBS. Cells were then stained with Hoechst $33258(5 \mu \mathrm{g} / \mathrm{ml})$ for $5 \mathrm{~min}$ at $4^{\circ} \mathrm{C}$. Nuclei were visualized under a fluorescence microscope at a wavelength of $360 \mathrm{~nm}$.

Oligonucleotide preparations. Antisense oligonucleotides to $\alpha$-syn were synthesized by Oligos (Wilsonville, OR). The first and last bases of each oligonucleotide sequence were phosphorothioated. The $\alpha$-syn antisense 
oligonucleotide sequence was 5'-GAACACATCCATGGCTAAAG-3', corresponding to a sequence of the rat $\alpha$-syn gene (GenBank cDNA clone NM_019169) flanking the mRNA translation initiation region. The $\alpha$-syn mismatch sequence was 5'-ATGGGGCATTTTAATAAACT-3'.

Transfection of $\alpha$-syn siRNA. CGCs were transfected with $\alpha$-syn and scrambled siRNA immediately before plating using electroporation with the Amaxa (Gaithersburg, MD) Nucleofector apparatus following the instructions of the manufacturer. The sequences of each of the four siRNAs to $\alpha$-syn are as follows: siRNA 1, GAAGAAGGGUACCCACAAGUU (sense) and 5'PCUUGUGGGUACCCUUCUUCUU (antisense); siRNA 2, CUAUGAGCCUGAAGCCUAAUU (sense) and 5'PUUAGGCUUCAGGCUCAUAGUU (antisense); siRNA 3, GGGAGUCGUUCAUGGAGUGUU (sense) and 5'PCACUCCAUGAACGACUCCCUU (antisense); siRNA 4, AAGAGCAAGUGACAAAUGUUU (sense) and 5'PACAUUUGUCACUUGCUCUUUU (antisense) (catalog number MU-090827-00-0005; Dharmacon RNA Technologies, Lafayette, CO). A SMART pool composed of a mixture of the above four siRNAs designed to specifically target rat $\alpha$-syn LOC367973 (catalog number M-090827-00-0010; Dharmacon RNA Technologies) was also used for transfection.

Measurement of HDAC activity. The activity of HDAC was measured using a commercial assay kit from Upstate Biotechnology, according to the protocol of the manufacturer. Briefly, biotinylated histone $\mathrm{H} 4$ peptide was radiolabeled with $\left[{ }^{3} \mathrm{H}\right]$ acetyl-CoA and then captured with the streptavidin-agarose slurry. Greater than $70 \%$ of $\left[{ }^{3} \mathrm{H}\right.$ ] acetate was found to be incorporated into $100 \mu \mathrm{g}$ of histone $\mathrm{H} 4$ peptide. The reaction mixture in a volume of $200 \mu \mathrm{l}$ contained $30 \mu \mathrm{g}$ of protein from freshly prepared cell lysates and $100 \times 10^{3}$ counts per minute of $\left[{ }^{3} \mathrm{H}\right]$ acetyl histone $\mathrm{H} 4$ peptide in the HDAC assay buffer. After incubation at $37^{\circ} \mathrm{C}$ overnight with shaking, the reaction was terminated by adding $50 \mu \mathrm{l}$ of quenching solution containing $\mathrm{HCl}$ and acetic acid, followed by centrifugation. The released $\left[{ }^{3} \mathrm{H}\right]$ acetate was determined by removing $100 \mu$ l of the supernatant and counting for radioactivity in a liquid scintillation counter.

Total RNA extraction and Oligo GEArray rat apoptosis microarray analysis of apoptotic genes. CGCs on DIV 0 were treated with $3 \mu \mathrm{m}$ antisense oligonucleotides to $\alpha$-syn. Four days later, cells were harvested and total RNA was extracted using Trizol reagent (Invitrogen, Carlsbad, CA). Hybridization and microarray analyses were performed by SuperArray Bioscience (Frederick, MD). Briefly, $3 \mu \mathrm{g}$ of total RNA was used as the initial RNA input to make the cRNA probe using a TrueLabeling-AMP 2.0 (SuperArray Bioscience). The biotin-UTD labeled cRNA was purified by using the cRNA clean-up kit (SuperArray Bioscience), and the cleaned cRNA was then used for hybridization using the OligoGE Array procedure. The array images were captured by a FluorChem 8900 (or FluorChem SP) system (Alpha Innotech, San Leandro, CA), and data were analyzed by GEArray Expression Analysis Suite software (SuperArray Bioscience).

$\alpha$-Syn promoter activity assays. A $1.9 \mathrm{~kb}$ DNA fragment upstream of the human $\alpha$-syn transcription initiation site containing exons 1,2 , and 3 (pASP-1.9) constructed as described previously (Chiba-Falek and Nussbaum, 2001) was kindly supplied by Dr. Robert L. Nussbaum (Genetic Disease Research Branch, National Human Genome Research Institute, National Institutes of Health, Bethesda, MD). CGCs were transfected with the pASP-1.9 luciferase reporter construct immediately before plating using electroporation with the Amaxa Nucleofector apparatus according to the instructions of the manufacturer. HEK 293T (HEK 293T) cells and neuroblastoma SH-SY5Y cells were cultured as described previously (Chiba-Falek and Nussbaum, 2001) and transfected with the pASP-1.9 luciferase reporter construct using Lipofectamine 2000 (Invitrogen). Enhanced green fluorescence protein (eGFP) and secreted alkaline phosphate were cotransfected to ensure that the transfection efficiencies were similar between drug-treated and untreated cultures. One day after transfection, cultures were treated with indicated concentrations of VPA, sodium 4-phenylbutyrate, and trichostatin A (TSA) (Calbiochem, San Diego, CA) for $24 \mathrm{~h}$. Cells were then harvested, lysed, and assayed for luciferase activity using the luciferase reporter assay system (Promega, Madison, WI) in conjunction with a luminometer. As a con- trol for the luciferase basal expression, a promoterless plasmid was also cotransfected, and the relative activity of luciferase was calculated.

Chromatin immunoprecipitation assay. Chromatin immunoprecipitation (ChIP) assays were performed using the ChIP-IT assay kit protocol as recommended by the manufacturer (Active Motif, Carlsbad, CA) with slight modifications. Briefly, $4 \times 10^{7}$ human neuroblastoma SH-SY5Y cells were transfected with the pASP-1.9 construct with Lipofectamine 2000 and then treated with VPA ( $1 \mathrm{~mm}$ ) or its vehicle $24 \mathrm{~h}$ later. After $24 \mathrm{~h}$ incubation, cells were cross-linked with $1 \%$ formaldehyde at $37^{\circ} \mathrm{C}$ for 10 min, repeatedly washed with ice-cold PBS and lysed, followed by centrifugation. The nuclear pellet was resuspended in shearing buffer and sonicated at $30 \%$ power, $6 \times 10 \mathrm{~s}$, using a sonicator (Sonics and Materials, Newtown, CT) to shear DNA into 200-1000 bp fragments. All of the samples were precleared with salmon sperm DNA/protein G agarose. Ten percent of the mixture of protein/DNA complex was taken for "input DNA" analysis. An equal amount of the protein/DNA complex was then incubated with an antibody against acetylated histone $\mathrm{H} 3(2 \mu \mathrm{g})$ at $4^{\circ} \mathrm{C}$ overnight, followed by incubation with salmon sperm DNA/protein $\mathrm{G}$ agarose for $2 \mathrm{~h}$. Immunoprecipitated DNA was then eluted from protein $\mathrm{G}$ agarose. The cross-linking was reversed and the DNA was purified. The $\alpha$-syn promoter region (GenBank accession number AF163864) was PCR amplified using forward primer 5 '-CGTGACCCTAAACTTAACGTG-3' (positions 28,045-28,065) and reverse primer 5'-AGAAGGCTTGAAGGCAAGGC-3' (position 28,444-28,425). Because RNA pol II is known to bind to the promoter region of the glyceraldehyde-3phosphate dehydrogenase (GAPDH) gene, DNA immunoprecipitated with anti-RNA pol II was subjected to PCR for GAPDH to serve as a positive reagent control for the ChIP assay. The GAPDH promoter sequences used were as follows: forward primer, 5'-TACTAGCGGTTTTACGGGCG-3'; reverse primer, 5'-TCGAACAGGAGGAGCAGAGAGCGA-3' (Active Motif). The PCR amplification was performed for 35 cycles.

Statistical analysis. Data are expressed as means \pm SEM from at least three independent experiments. Statistical significance was analyzed by one-way ANOVA and the Bonferroni's post hoc test. A $p$ value of $\leq 0.05$ was considered significant.
A

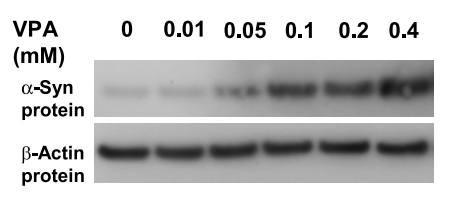

B
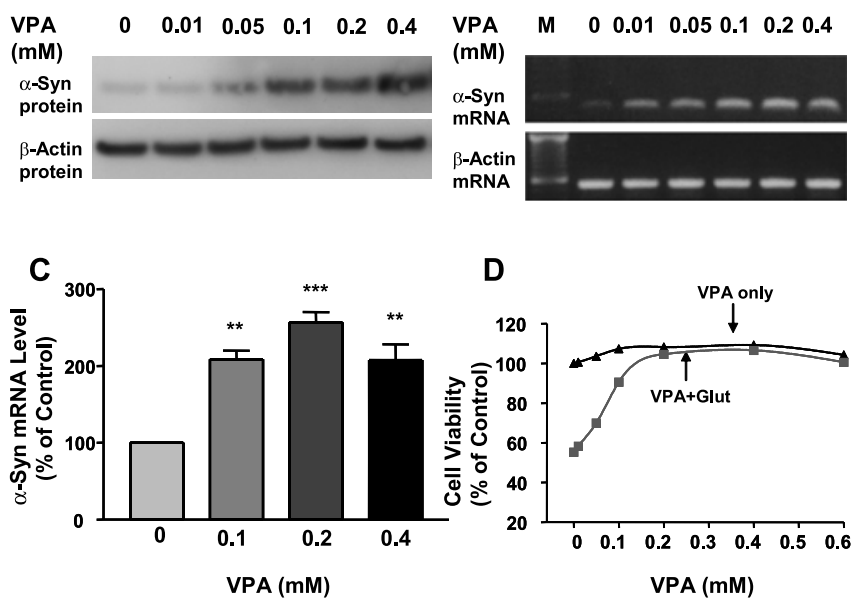

D

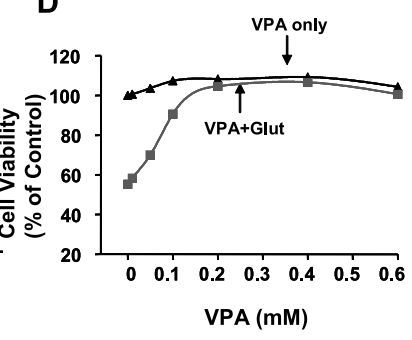

Figure 1. VPA treatment increases the levels of $\alpha$-syn protein and mRNA and protects against glutamate-induced excitotoxicity in $\mathrm{CGC}$ neurons. CGCs were treated with the indicated concentrations of VPA for $6 \mathrm{~d}$ starting from DIV 1. $\alpha$-Syn protein levels were then determined by Western blotting $(\boldsymbol{A})$ and $\alpha$-syn mRNA levels by RT-PCR $(\boldsymbol{B})$. The left lane in $\boldsymbol{B}$ shows the sizes of the DNA marker (M). Levels of $\beta$-actin protein and mRNA were used as the control in $\boldsymbol{A}$ and $\boldsymbol{B}$, respectively. $\alpha$-Syn mRNA levels were also quantified by real-time PCR in CGCs treated with vehicle and $0.1,0.2$, and $0.4 \mathrm{~mm} \mathrm{VPA} \mathrm{for} 6 \mathrm{~d}(\boldsymbol{C})$. Data are means \pm SEM of percentage of control from three independent experiments. ${ }^{* *} p<0.01 ;{ }^{* * *} p<0.001$ compared with the vehicle control. VPA-pretreated CGCs were also exposed to vehicle or $100 \mu \mathrm{m}$ glutamate (glut) on DIV 7 for $24 \mathrm{~h}$ and then analyzed for cell viability by MTT assay (D). Data are presented as means \pm SEM of percentage of untreated control from five to six independent cultures. 
A

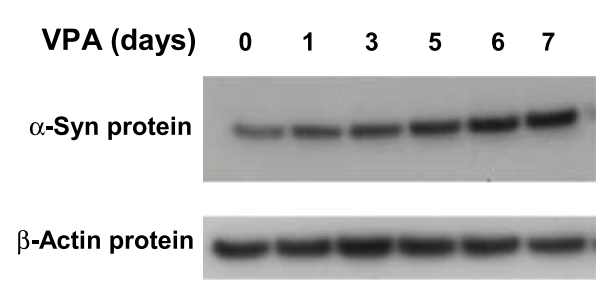

B

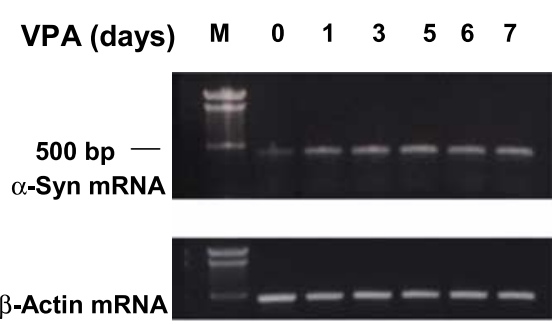

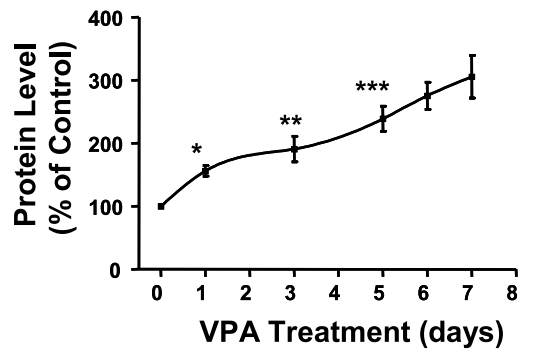

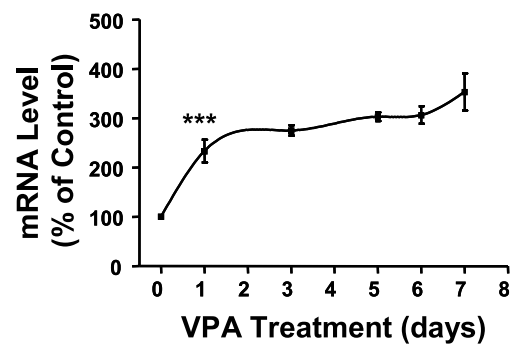

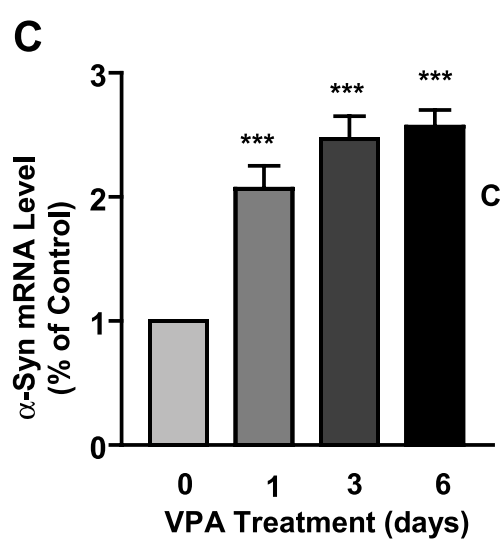

D $\alpha$-Syn /Rhodamine DAP
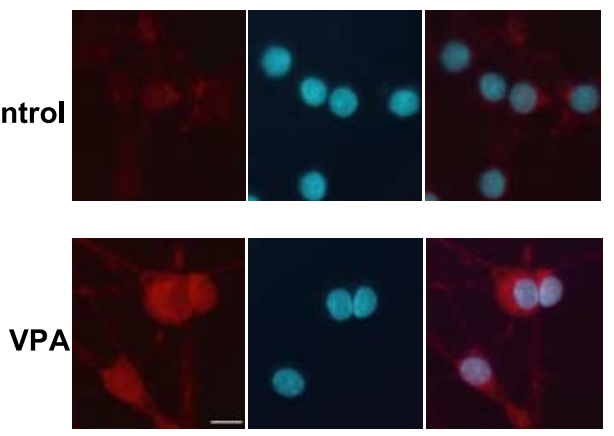

Figure 2. VPA-induced increase in the levels of $\alpha$-syn protein and mRNA is duration dependent. CGCs were treated with $0.4 \mathrm{~mm}$ VPA for 1-6d, and all cultures were harvested on DIV 7 for Western blotting of $\alpha$-syn protein levels $(\boldsymbol{A})$ and RT-PCR of $\alpha$-syn mRNA levels $(\boldsymbol{B})$. The left lane in $\boldsymbol{B}$ is the DNA marker (M). Levels of $\beta$-actin protein and mRNA were used as the control in $\boldsymbol{A}$ and $\boldsymbol{B}$, respectively. Quantified results are shown in the respective right panels in $\boldsymbol{A}$ and $\boldsymbol{B}$ and are expressed as means \pm SEM of four independent experiments. ${ }^{*} p<0.05 ;{ }^{* *} p<0.01$; ${ }^{* * *} p<0.001$ compared with the 0 time control. $\alpha$-Syn mRNA levels were also quantified by real-time PCR in CGCs treated with $0.4 \mathrm{~mm}$ VPA for 1, 3, and $6 \mathrm{~d}$ (C). Data are means \pm SEM of three independent experiments. ${ }^{* * *} p<0.001$ compared with 0 time control. VPA-treated and untreated CGC cultures were also examined for $\alpha$-syn immunofluorescence as described in Materials and Methods (D). $\alpha$-Syn immunostaining was identified by incubation with goat anti-mouse Rhodamine Red-X-AffiniPure-conjugated secondary antibody and is shown in red, and the nuclear staining by DAPI is shown in blue. The overlay images are also shown. Scale bar, $10 \mu \mathrm{m}$.

\section{Results}

VPA increases levels of $\alpha$-syn protein and mRNA in rat CGCs Treatment of CGC cultures with VPA for $6 \mathrm{~d}$, starting from DIV 1 , caused a concentration-dependent increase in the levels of $\alpha$-syn protein (Fig. 1A). The increase was detected at a VPA concentration as low as $0.05 \mathrm{~mm}$ and further increased in a dosedependent manner from 0.1 to $0.4 \mathrm{~mm}$. The VPA-induced increase in $\alpha$-syn protein was associated with an increase in the levels of $\alpha$-syn mRNA as determined by RT-PCR (Fig. $1 B$ ). In contrast, levels of $\beta$-actin protein and mRNA were unchanged by VPA treatment. Quantitative real-time RT-PCR confirmed VPAinduced increase in $\alpha$-syn mRNA levels (Fig. 1C). VPA pretreatment for $6 \mathrm{~d}$ protected CGC neurons from glutamate-induced excitotoxicity with a dose requirement similar to that for upregu- lating $\alpha$-syn mRNA and protein (Fig. $1 D$ ). The VPA-induced elevation of $\alpha$-syn protein and mRNA progressively increased with exposure time, reaching a maximum after $\sim 6 \mathrm{~d}$ of treatment (Fig. $2 A, B$ ). Realtime RT-PCR also showed a twofold to threefold increase in $\alpha$-syn mRNA levels after VPA treatment for 1, 3, and $6 \mathrm{~d}$ (Fig. $2 C)$. Immunocytochemical staining revealed that the intensity of $\alpha$-syn immunofluorescence in CGCs was robustly increased by VPA treatment, and the enhanced $\alpha$-syn immunofluorescence was predominantly found in the cytoplasm and processes of CGC neurons (Fig. 2D).

$\alpha$-Syn knockdown blocks VPA-induced upregulation of $\alpha$-syn and neuroprotection against glutamate excitotoxicity

We next used the antisense knock-out method to assess the role of $\alpha$-syn upregulation in VPA-induced neuroprotection against glutamate excitotoxicity. Morphological inspection showed that glutamateinduced neuronal degeneration was blocked by VPA pretreatment, and this VPA neuroprotection was prevented by the presence of antisense, but not mismatch, oligonucleotides to $\alpha$-syn (Fig. $3 A)$. Staining with Hoechst dye 33258 revealed that glutamate treatment induced extensive chromatin condensation, a hallmark of apoptosis, which was prevented by VPA treatment, and this aspect of VPA neuroprotection was also blocked by antisense but not mismatch oligonucleotides (Fig. 3B). Quantification of viable cells by MTT assay substantiated the blocking effect of $\alpha$-syn antisense oligonucleotides on VPA neuroprotection (Fig. 3C). $\alpha$-Syn oligonucleotides did not affect viability of untreated CGC cultures (data not shown). Western blotting was then performed to ascertain the specificity of the $\alpha$-syn oligonucleotides. VPA-induced $\alpha$-syn protein increase was suppressed by pretreatment with 3 or $5 \mu \mathrm{M} \alpha$-syn antisense oligonucleotides, whereas the mismatch oligonucleotides were ineffective (Fig. 4A). The VPA-induced increase in $\alpha$-syn protein was also observed in CGCs treated with glutamate (Fig. $4 B$ ). Under all experimental conditions, the levels of $\beta$-actin protein were essentially unchanged. To further examine for the specificity of induction by VPA, we measured the levels of $14-3-3 \epsilon$, a protein that binds $\alpha$-syn, shares its physical and functional homology, and is present in part in the synaptic membrane to modulate neurotransmission (Ostrerova et al., 1999; Simsek-Duran et al., 2004). The levels of 14-3-3 protein were found to be unchanged by treatment with VPA or $\alpha$-syn antisense oligonucleotides (Fig. 4C).

The siRNA methodology was further used to silence the expression of $\alpha$-syn. Transfection of CGCs with a pool of four siRNAs for $\alpha$-syn resulted in a reduction of basal and upregulated 
A

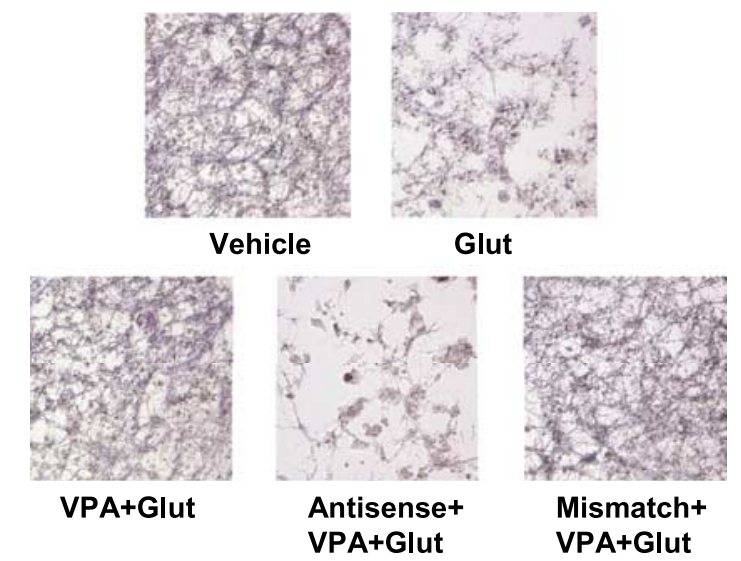

B

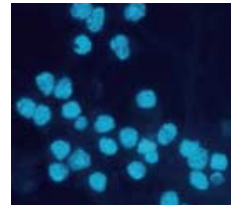

Vehicle

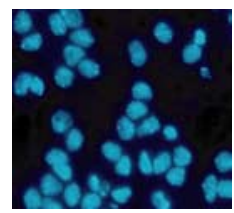

VPA+Glut

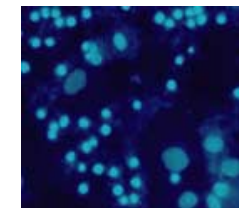

Antisense+ VPA+Glut

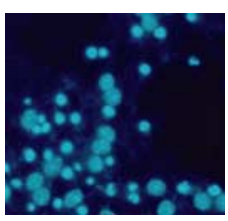

Glut

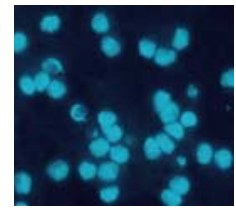

Mismatch+ VPA+Glut

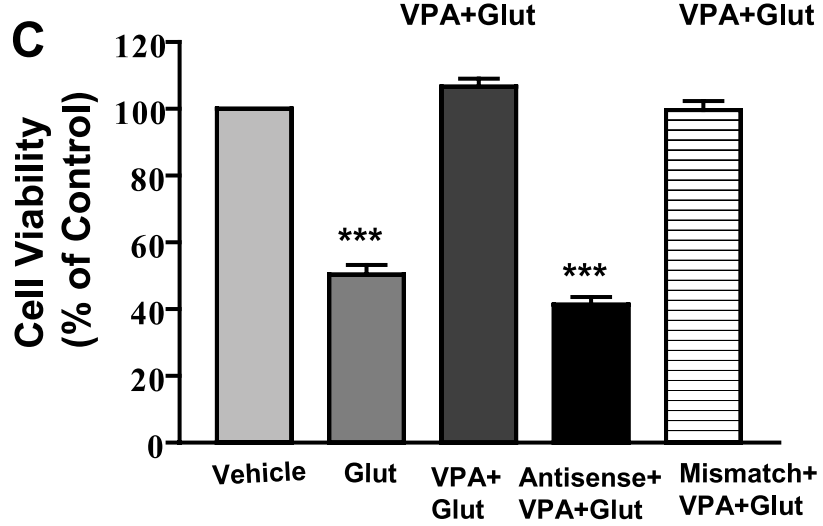

Figure 3. Antisense, but not mismatch, oligonucleotides to $\alpha$-syn block VPA-induced protection of CGCs from glutamate excitotoxicity. Cells were exposed to antisense or mismatch oligonucleotides $(3 \mu \mathrm{m})$ for $24 \mathrm{~h}$ before pretreatment with $0.4 \mathrm{~mm}$ VPA (DIV 1 to DIV 7 ) and subsequent treatment with glutamate (Glut; $100 \mu \mathrm{m}$ ) for $24 \mathrm{~h}$. All cultures were stained with MTT $(\boldsymbol{A})$ or Hoechst dye $33258(\boldsymbol{B})$ and then photographed. Cell viability was quantified by MTT assay and expressed as means \pm SEM of vehicle-treated control from four independent cultures (C). ${ }^{* *} p<0.001$ compared with vehicle-treated control.

levels of $\alpha$-syn protein (Fig. 5A). Treatment with the $\alpha$-syn siRNA pool, but not scrambled siRNA, blocked the neuroprotective effects of VPA against excitotoxicity (Fig. 5B). Moreover, exposure of untreated CGCs to the siRNA pool for $\alpha$-syn, but not scrambled siRNA, markedly enhanced the sensitivity to glutamateinduced cell death (Fig. $5 C$ ). Thus, $\sim 70 \%$ of siRNA-treated cells were lost by the presence of $10 \mu \mathrm{M}$ glutamate, as opposed to only $30 \%$ neuronal death in cultures not treated with siRNA. The maximal extent of glutamate-induced neuronal death was also potentiated by $\alpha$-syn siRNA. Similar sensitization to glutamate excitotoxicity was observed by treating CGCs with $\alpha$-syn antisense oligonucleotides (data not shown). When each of the four
A
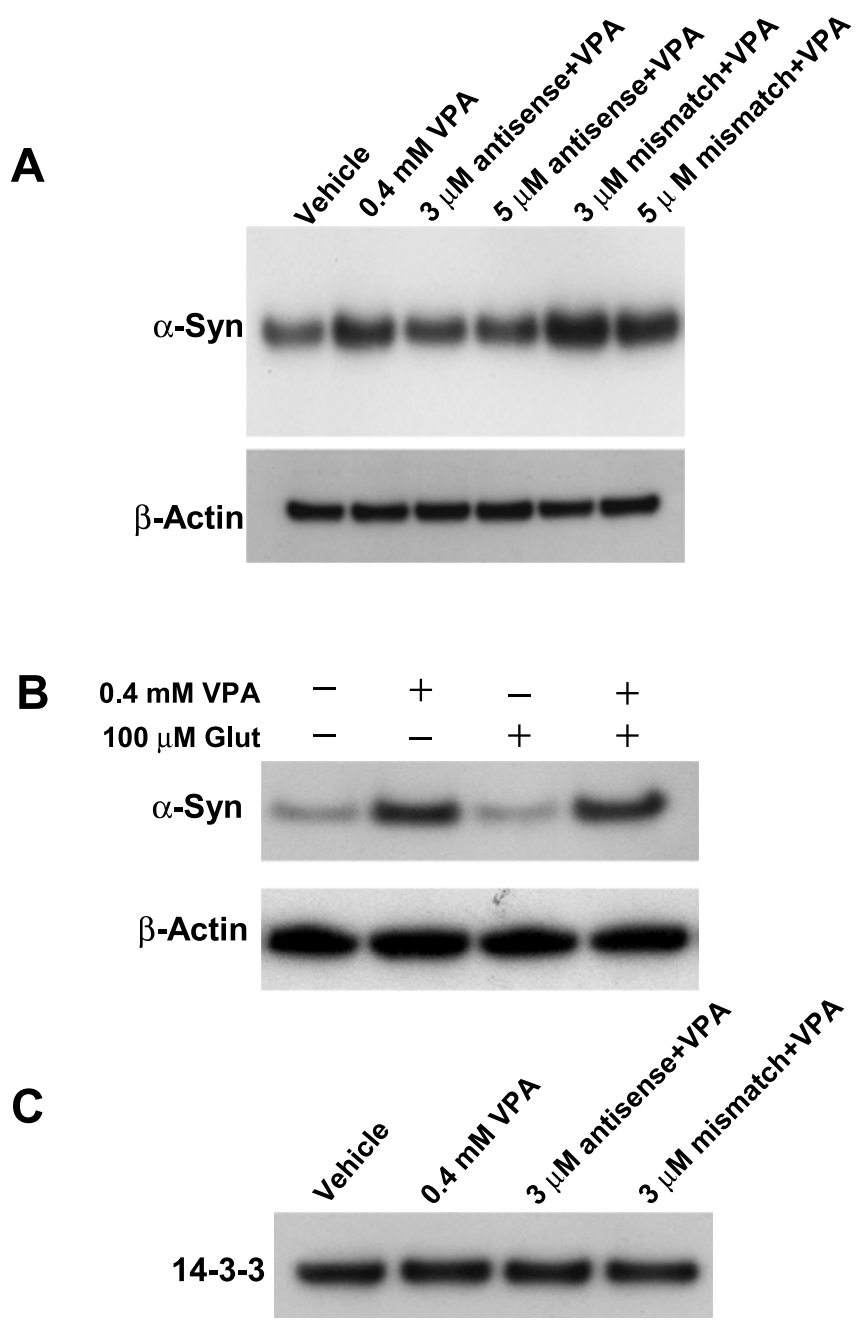

Figure 4. Antisense, but not mismatch, oligonucleotides to $\alpha$-syn block VPA-induced increase in $\alpha$-syn protein levels, and VPA prevents glutamate-induced $\alpha$-syn downregulation. $\boldsymbol{A}$, CGCs were exposed to 3 or $5 \mu \mathrm{m}$ antisense or mismatch oligonucleotides for $24 \mathrm{~h}$ before treatment with $0.4 \mathrm{~mm}$ VPA for $6 \mathrm{~d}$ (DIV 1 to DIV 7). Cells were then harvested for Western blotting of $\alpha$-syn. Levels of $\beta$-actin were used as the loading control. $\boldsymbol{B}$, Cells were treated with $0.4 \mathrm{~mm} \mathrm{VPA}$ for $6 \mathrm{~d}$ (DIV 1 to DIV 7), followed by treatment with $100 \mu \mathrm{m}$ glutamate (Glut) for $24 \mathrm{~h}$. Western blotting of $\alpha$-syn and $\beta$-actin was then performed, and the blots of a typical experiment are shown. C, Cells were exposed to $3 \mu \mathrm{m}$ antisense oligonucleotides to $\alpha$-syn for $24 \mathrm{~h}$ before treatment with $0.4 \mathrm{~mm}$ VPA for $6 \mathrm{~d}$ (DIV 1 to DIV 7). Western blotting for $14-3-3$ protein was then performed using an antibody against 14-3-3 (1:1000; BD Transduction Laboratories).

$\alpha$-syn siRNAs was individually tested, it was found to be effective in reducing basal and VPA-induced $\alpha$-syn protein levels (Fig. $6 A, B)$, as well as in exacerbating glutamate toxicity and inhibiting VPA neuroprotection (Fig. 6C,D). Recent evidence indicates that upregulation of interferon may be a useful indicator of nonspecific siRNA effects. The double-stranded RNA-dependent protein kinase PKR, which is activated in type 1 interferon response (for review, see Bantounas et al., 2004), phosphorylates the small subunit of eIF $2 \alpha$, resulting in nonspecific inhibition of translation (Manche et al., 1992). Our results showed that the phosphorylation level of eIF $2 \alpha$ was not increased by treatment with any of these $\alpha$-syn siRNAs (Fig. 6E), confirming the $\alpha$-syn siRNA specificity.

Antisense oligonucleotides to $\alpha$-syn upregulate Ube2n but downregulate Bcl-2 mRNA

Because $\alpha$-syn antisense oligonucleotides blocked VPA-induced protection against glutamate excitotoxicity, an Oligo GEArray 
A

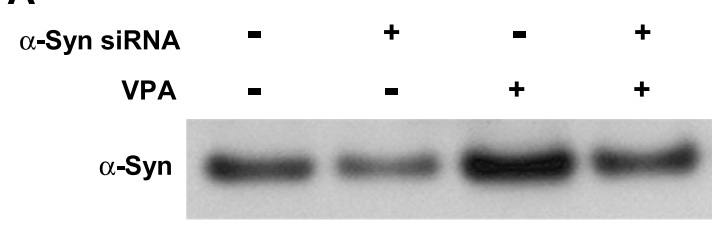

B

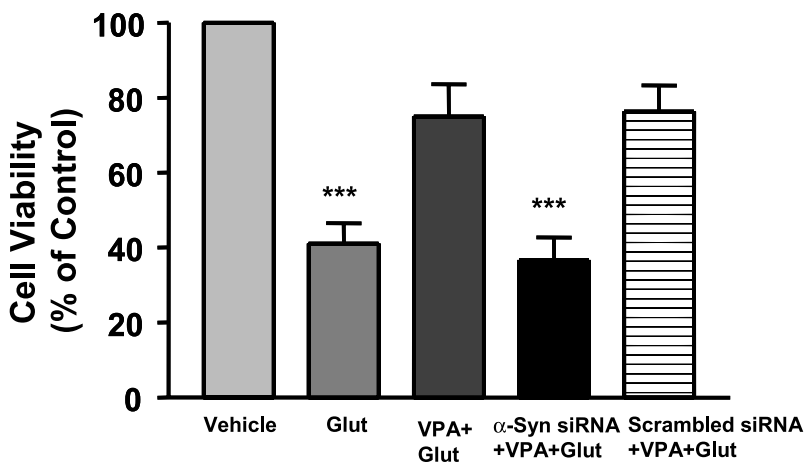

C

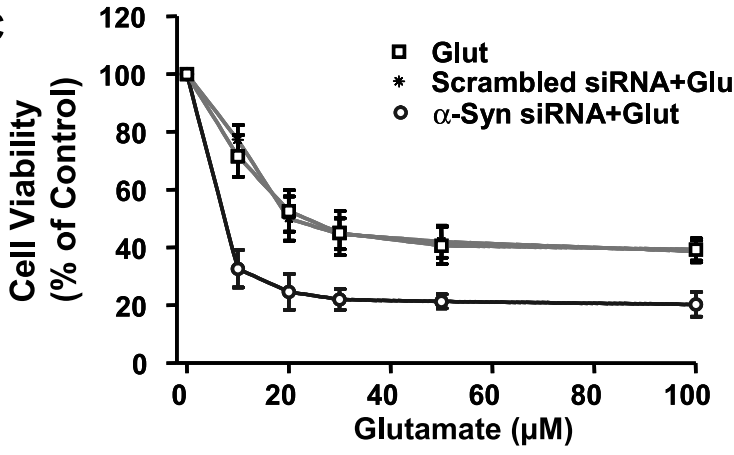

Figure 5. $\alpha$-Syn siRNA pool suppresses VPA-induced increase of $\alpha$-syn protein, blocks VPAinduced protection, and facilitates glutamate excitotoxicity. Cells were exposed to $\alpha$-syn siRNA pool (100 nm) or scrambled siRNA ( $100 \mathrm{~nm}$ ) for $24 \mathrm{~h}$ before pretreatment with $0.4 \mathrm{~mm}$ VPA for $6 \mathrm{~d}$ (DIV 1 to DIV 7). Cells were either harvested for Western blot $(\boldsymbol{A})$ or subsequently treated with glutamate (Glut; $100 \mu \mathrm{m})$ for $24 \mathrm{~h}(\boldsymbol{B})$. Cells were also exposed to $\alpha$-syn siRNA pool or its scrambled siRNA control for $6 \mathrm{~d}$ (DIV 1 to DIV 7) and then exposed to the indicated concentration of glutamate for $24 \mathrm{~h}$ (C). Cell viability was quantified by MTT assay and expressed as means \pm SEM of vehicle-treated control from three independent cultures. ${ }^{* * *} p<0.001$ compared with vehicle-treated control.

Rat Apoptosis Microarray was used to assess changes in mRNA levels in CGCs treated with the antisense oligonucleotides for $4 \mathrm{~d}$. Twelve genes were found to be upregulated, and one gene was downregulated by the $\alpha$-syn antisense treatment (Table 1). The proteins encoded by the upregulated genes are involved in apoptosis induction, caspase activation, and ubiquitin regulation, whereas the downregulated gene Bcl-2 has a prominent role in anti-apoptosis and cytoprotection. One of the upregulated genes, Ube2n, which is associated with apoptosis and has ubiquitinconjugating enzymatic activity (Habelhah et al., 2004), and the downregulated Bcl-2 gene were further analyzed by RT-PCR and real-time RT-PCR to confirm their respective mRNA upregulation and downregulation (Fig. $7 A, B$ ). RT-PCR and real-time RTPCR analyses also showed that Ube2n mRNA upregulation by $\alpha$-syn antisense treatment occurred in the presence of VPA (Fig. $7 C, D$ ). Moreover, Bcl-2 mRNA was increased by VPA treatment, and this increase was blocked by $\alpha$-syn antisense oligonucleotides. Western blotting analysis confirmed that $\alpha$-syn antisense treatment upregulated the protein level of Ube2n but downregulated that of $\mathrm{Bcl}-2$ in both untreated and VPA-treated CGCs (Fig. 7E,F).
A

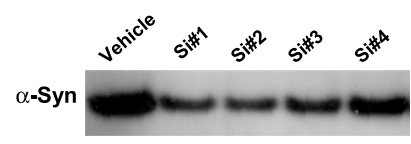

B

C

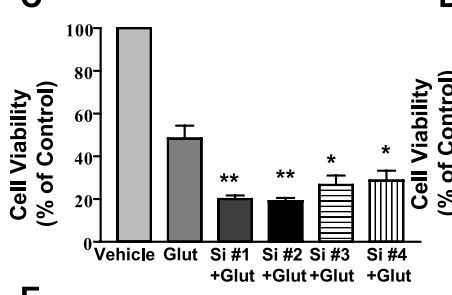

D

E
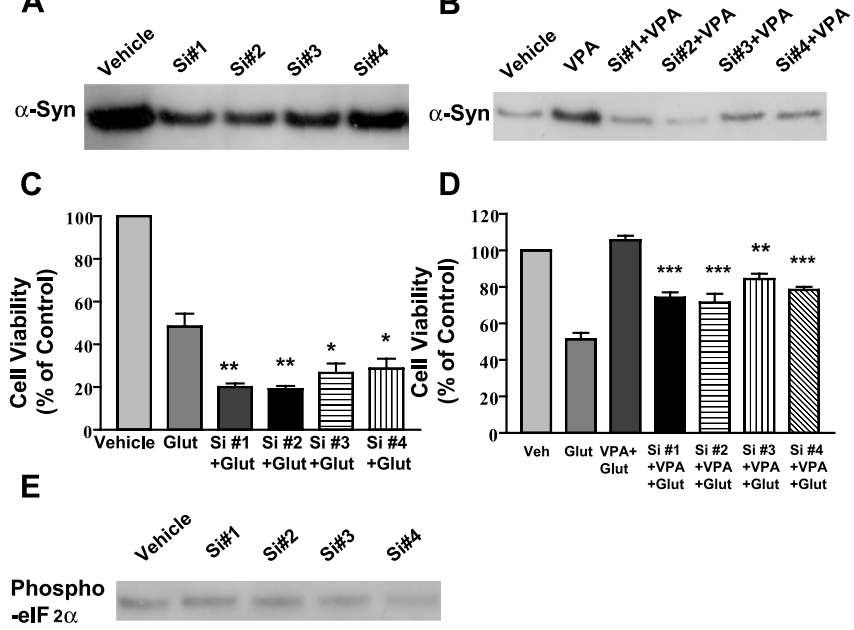

Figure 6. Individual siRNA decreases basal and VPA-stimulated $\alpha$-syn protein levels, exacerbates glutamate-induced excitotoxicity, and attenuates VPA neuroprotection. Cells were exposed to $100 \mathrm{~nm}$ individual $\alpha$-syn siRNA (S\#1, S\#2, S\#3, or S\#4) for $24 \mathrm{~h}$ before pretreatment with vehicle or $0.4 \mathrm{~mm}$ VPA for $6 \mathrm{~d}$ (DIV 1 to DIV 7). Cells were then harvested for Western blotting of $\alpha$-syn protein $(\boldsymbol{A}, \boldsymbol{B})$ or further incubated without or with glutamate (Glut; $100 \mu \mathrm{M}$ ) for $24 \mathrm{~h}(\boldsymbol{C}, \boldsymbol{D})$. Cell viability was quantified by MTT assay from three independent cultures. ${ }^{*} p<$ 0.05 ; ${ }^{* *} p<0.01$ compared with glutamate group in $C$. ${ }^{* *} p<0.01$; ${ }^{* * *} p<0.001$ compared with VPA plus glutamate group in $\boldsymbol{D}$. Cell lysates from $\boldsymbol{A}$ were also used for immunoblotting of phospho-elF $2 \alpha$ protein levels $(\boldsymbol{E})$. Western blots are results from a typical experiment.

\section{HDAC inhibition participates in VPA-induced upregulation} of $\alpha$-syn

Because VPA is an inhibitor of HDAC (Phiel et al., 2001; Göttlicher et al., 2001), we investigated whether the VPA induction of $\alpha$-syn was mediated by inhibition of HDAC. Initial experiments showed that levels of acetylated histone $\mathrm{H} 3$ were increased by VPA modestly at 0.01 and $0.05 \mathrm{~mm}$, robustly at 0.1 and $0.2 \mathrm{~mm}$, and dramatically at $0.4 \mathrm{~mm}$ (Fig. $8 \mathrm{~A}$ ). These results suggested that VPA also inhibits HDAC over a wide concentration range of this drug. Direct measurements of HDAC activity using $\left[{ }^{3} \mathrm{H}\right]$ acetyl histone $\mathrm{H} 4$ as the substrate confirmed the inhibition of HDAC by VPA in a dose-dependent manner (Fig. 8B). Conversely, treatment of CGCs with glutamate resulted in a dose-dependent decrease in the levels of acetylated histone $\mathrm{H} 3$ with a concomitant reduction in $\alpha$-syn levels (Fig. $8 C$ ). Next, we examined whether VPA induction of $\alpha$-syn was mimicked by other inhibitors of HDAC, sodium 4-phenylbutyrate and TSA. We found that phenylbutyrate also induced $\alpha$-syn and increased the acetylated histone $\mathrm{H} 3$ levels in a concentration-dependent manner in the range of 0.125-1 mm (Fig. 9A). Similarly, TSA increased the levels of $\alpha$-syn and acetylated histone $\mathrm{H} 3$ in a concentration-dependent manner in the range of 10-200 nM (Fig. 9B). Moreover, these effects of phenylbutyrate and TSA were associated with protection against glutamate excitotoxicity (Fig. 9C,D). Finally, we determined whether the VPA induction of $\alpha$-syn was also found in other neuronal cell types. The results showed that $\alpha$-syn protein was concentration dependently increased by VPA treatment in rat cerebral cortical neurons in the dose range $(0.25-1 \mathrm{mM})$ examined (Fig. 10). The induction of $\alpha$-syn was associated with hyperacetylation of histone $\mathrm{H} 3$ and with no effect on $\beta$-actin levels. The effects of HDAC inhibitors on $\alpha$-syn protein levels were also examined in cerebellum and the frontal cortex of rats repeatedly injected with VPA ( $300 \mathrm{mg} / \mathrm{kg}$, s.c.), sodium butyrate (SB) $(300 \mathrm{mg} / \mathrm{kg}$, s.c.), or TSA $(0.2 \mathrm{mg} / \mathrm{kg}$, s.c.) for $4 \mathrm{~d}$. The $\alpha$-syn protein levels were found to be markedly increased in both brain areas by treatment with each of these HDAC inhibitors (Fig. 11) 
compared with their respective vehicle control. The levels of $\beta$-actin were unchanged in these two brain regions after treatments.

HDAC inhibitors increase the promoter activity of $\alpha$-syn and enhance histone $\mathrm{H} 3$ acetylation levels in the $\alpha$-syn promoter To assess whether the enhanced levels of $\alpha$-syn mRNA and protein are triggered by an increase in $\alpha$-syn promoter activity, CGCs, HEK 293T cells, and human neuroblastoma SH-SY5Y cells were transfected with a $1.9 \mathrm{~kb}$ DNA fragment upstream of the human $\alpha$-syn transcription initiation site (pASP-1.9). This pASP-1.9 construct has been shown to express the maximal promoter activity in SH-SY5Y cells and near maximal activity in HEK 293T cells (Chiba-Falek and Nussbaum, 2001). One day after transfection, CGCs, HEK 293T cells, and SH-SY5Y cells were treated with VPA (1 mM), phenylbutyrate (2 $\mathrm{mm}$ ), or TSA (50 nM) for $24 \mathrm{~h}$. eGFP and secreted alkaline phosphates were also cotransfected to ensure that the transfection efficiencies were similar between drug-treated and untreated groups. The $\alpha$-syn promoter activity was then assayed in this luciferase reporter system. Treatment with VPA induced an increase in the $\alpha$-syn promoter activity in CGCs and HEK 293T cells and even a more robust effect in SH-SY5Y cells (Fig. 12 A). Similar increases in $\alpha$-syn promoter activity were observed in all three cell types treated with phenylbutyrate or TSA (Fig. 12 B, C).

Finally, we performed a ChIP assay to investigate whether VPA-induced $\alpha$-syn expression was associated with an increased level of histone acetylation in the promoter region of $\alpha$-syn. Because the most robust increase of $\alpha$-syn promoter activity was seen in SH-SY5Y cells, these cells were transfected with pASP-1.9 at $90 \%$ confluence and, $24 \mathrm{~h}$ later, were treated with $1 \mathrm{~mm} \mathrm{VPA}$ for $24 \mathrm{~h}$. After cross-linking of cells with formaldehyde, nuclei were isolated and subjected to sonication. The sheared chromatin was immunoprecipitated without or with an antibody against acetylated histone $\mathrm{H} 3$. The immunoprecipitated DNA was then purified and PCR amplified. The results showed that VPA treatment caused a significant increase in the levels of acetylated histone $\mathrm{H} 3$ in the $\alpha$-syn promoter (Fig. $13 A-C$ ), whereas the ChIP/ PCR positive "reagent" control of the GAPDH promoter showed no change by VPA. No detectable signal was observed when antihistone $\mathrm{H} 3$ antibody was omitted in the immunoprecipitation process. An even greater increase in acetylated histone $\mathrm{H} 3$ in the $\alpha$-syn promoter was observed in SH-SY5Y cells not transfected with pASP-1.9 (results not shown).

\section{Discussion}

Our novel results demonstrate that VPA treatment caused a timeand concentration-dependent increase in levels of $\alpha$-syn mRNA and protein in CGC neurons. These effects required several days of treatment and occurred below or within the therapeutic plasma levels of VPA (0.35-1.0 mM) used in treating seizures and bipolar disorder (McEloroy and Keck, 1995). Dose-dependent upregulation of $\alpha$-syn was also found in rat cerebral cortical neurons treated with VPA, suggesting that the $\alpha$-syn induction is not restricted to CGCs. The involvement of $\alpha$-syn in VPA-induced neuroprotection is strongly supported by the results that knockdown of upregulated $\alpha$-syn by its antisense oligonucleotides or

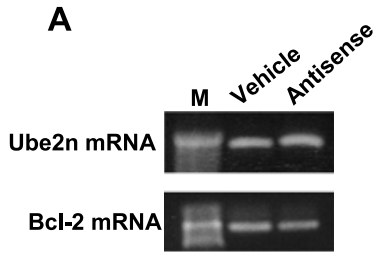

$\begin{array}{ll}\text { NM_172322 } & \text { Induction of apoptosis } \\ \text { NM_053812 } & \text { Induction of apoptosis }\end{array}$

NM_017059 Induction of apoptosis

NM_031328 Induction of apoptosis

NM_053736 Caspase activity

NM_013091 Tumor necrosis factor receptor

NM_145765 Caspase activation

NM_030989 Induction of apoptosis

NM_057205 NEDD8 activating enzyme activity, apoptosis

NM_031237 Ubiquitin-protein ligase activity

NM_053928 Ubiquitin-conjugating enzyme activity, apoptosis

1.96 NM_053928

NM_016993

Anti-apoptosis

$0.58 \quad$ NM_016993 Anti-apoptosis
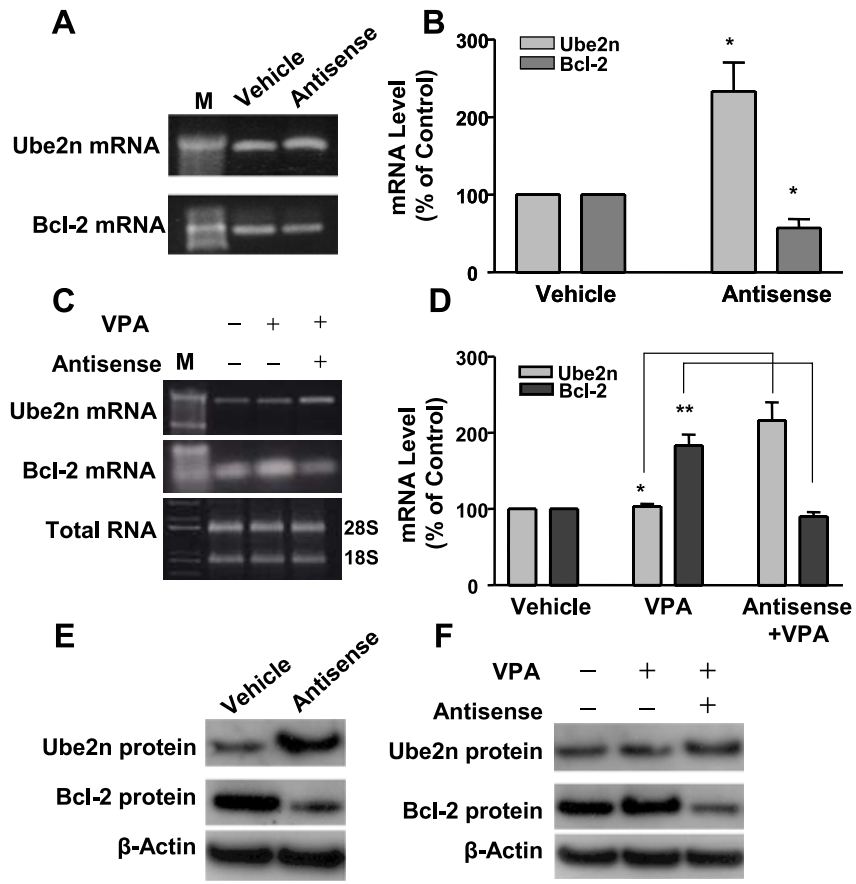

Figure 7. $\alpha$-Syn antisense oligonucleotides upregulate Ube2n but downregulate $\mathrm{BCl}-2$ mRNA and differentially affect VPA-induced levels of these proteins. CGCs on DIV 0 were treated with $3 \mu \mathrm{m}$ antisense oligonucleotides for $\alpha$-syn. Four days later, cells were harvested and total RNA was extracted. Ube2n and BCl-2 genes were analyzed for their mRNA levels by RT-PCR $(\boldsymbol{A})$ and quantified by real-time $P C R ;{ }^{*} p<0.05$ compared with respective vehicle in $B$. CGCs were also treated with $3 \mu \mathrm{m}$ antisense oligonucleotides for $\alpha$-syn on DIV 0 , followed by treatment with $0.4 \mathrm{~mm}$ VPA on DIV 1. Cells were harvested on DIV 4 for analysis of Ube2n and BCl-2 mRNA levels by RT-PCR $(\boldsymbol{C})$ and real-time RT-PCR $(\boldsymbol{D}) .{ }^{*} p<0.05 ;{ }^{* *} p<0.01$ between indicated groups. M, DNA marker. Western blotting were also performed to verify the antisense-induced changes in Ube2n and Bcl-2 protein levels in $\mathrm{GGCS}$ without and with VPA treatment $(\boldsymbol{E}, \boldsymbol{F})$. The Western blots are from a typical experiment.

siRNA completely blocked VPA-induced neuroprotection against glutamate-elicited chromatin condensation and apoptotic cell death. Exogenous or transfected $\alpha$-syn has been reported to protect against a number of apoptotic paradigms, including serum deprivation, oxidative stress, staurosporine, 1-methyl-4phenylpyridinium, and $\beta$-amyloid peptide in various cell types (Alves da Costa et al., 2002; Seo et al., 2002; Jensen et al., 2003). To our knowledge, this is the first demonstration of the neuropro- 
A $\begin{array}{llllllll}\operatorname{VPA}(\mathrm{mM}) & 0 & 0 & 0.01 & 0.05 & 0.1 & 0.2 & 0.4\end{array}$

\section{Acetylated H3}

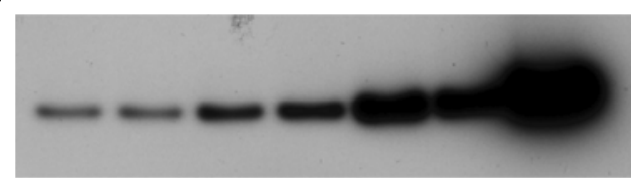

B

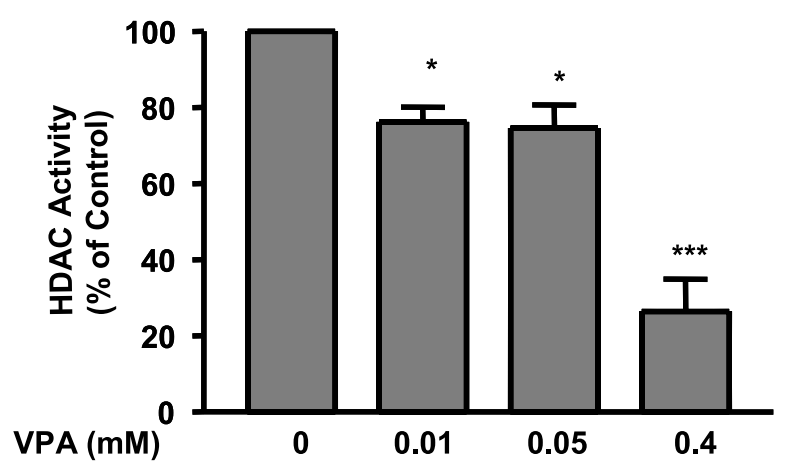

C

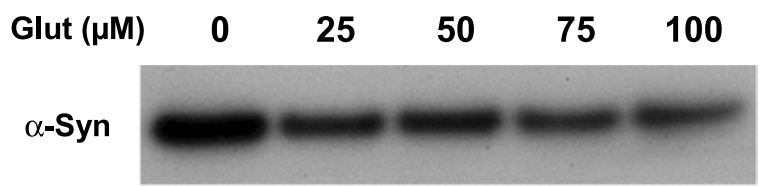

\section{Acetylated H3}

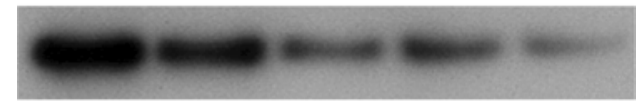

$\beta$-Actin

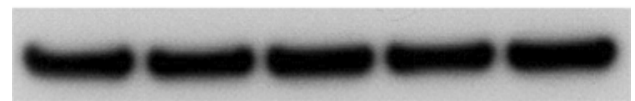

Figure 8. Histone $\mathrm{H} 3$ acetylation and $\alpha$-syn levels are dose-dependently increased by VPA but decreased by glutamate treatment. CGCs were treated with the indicated concentration of VPA for $6 \mathrm{~d}$ (from DIV 1 to DIV 7). Cells were then harvested for Western blotting of acetylated histone $\mathrm{H3}(\boldsymbol{A})$ and measurement of HDAC activity $(\boldsymbol{B})$. CGCs were also treated with glutamate (100 $\mu \mathrm{m}$; Glut) on DIV 7 for $24 \mathrm{~h}$ (C). Cells were then harvested for Western blotting of $\alpha$-syn, acetylated histone $H 3$, and $\beta$-actin. The quantified results are means \pm SEM of vehicle-treated control from three independent experiments. ${ }^{*} p<0.05$; ${ }^{* * *} p<0.001$ compared with the vehicle-treated control.

tective effects of endogenous $\alpha$-syn being increased by a therapeutic drug. In most reports, $\alpha$-syn is regarded as a protein capable of inducing neurotoxic effects and participating in the pathophysiology of neurodegenerative disorders such as Parkinson's and Alzheimer's diseases (for review, see Dawson and Dawson, 2003). It is conceivable that the neurotoxic effects of $\alpha$-syn depend on its presence in high concentrations, aggregated physical states, gene mutations, specific intracellular compartmentalization, and/or interactions with other protein molecules such as chaperone 14-3-3 and synphilin-1 proteins (Ostrerova et al., 1999; Kawamata et al., 2001).

Interestingly, treatment of CGCs with $\alpha$-syn siRNA (Fig. 5) or its antisense oligonucleotides (data not shown) facilitated glutamate-induced excitotoxicity in the absence of VPA. Oligo GEArrays were performed to identify apoptosis-related genes whose expression was altered by $\alpha$-syn knockdown. The expression of the prominent anti-apoptotic gene Bcl-2 was found to be downregulated after $\alpha$-syn antisense oligonucleotide treatment
A

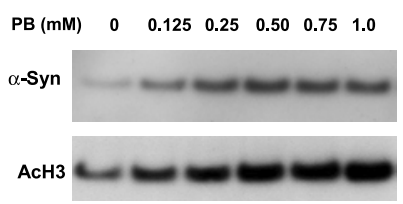

B

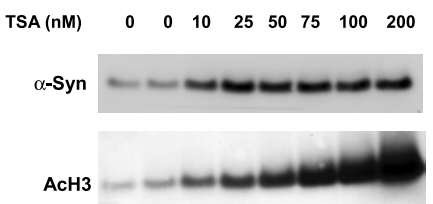

C

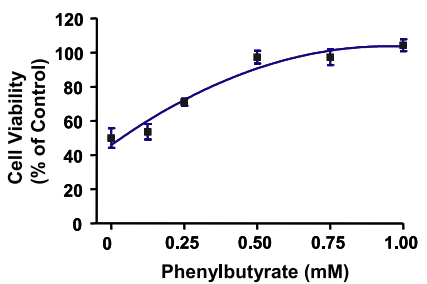

D

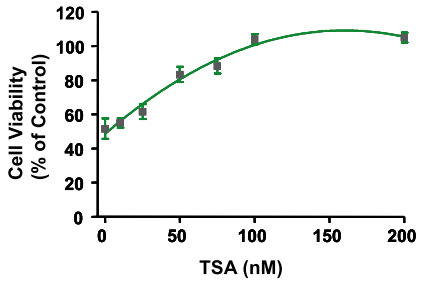

Figure 9. HDAC inhibitors phenylbutyrate and TSA mimic VPA to induce $\alpha$-syn, increase histone $\mathrm{H} 3$ acetylation (AC-H3), and protect against glutamate excitotoxicity. CGCs were treated with indicated concentrations of sodium 4-phenylbutyrate (PB) for $6 \mathrm{~d}(\boldsymbol{A})$ or TSA for $2 \mathrm{~d}(\boldsymbol{B})$, starting from DIV 1 or DIV 5 , respectively. Longer exposure of cells to high concentrations of TSA resulted in cytotoxicity. Cells were then harvested for Western blotting of $\alpha$-syn and acetylation histone H3 levels. PB- or TSA-treated cells were also exposed to glutamate (100 $\mu \mathrm{M})$ on DIV 7 for $24 \mathrm{~h}$ and then assayed for cell viability by MTT analysis $(\boldsymbol{C}, \boldsymbol{D})$. Quantified data expressed as percentage of untreated control are means \pm SEM from three independent experiments.

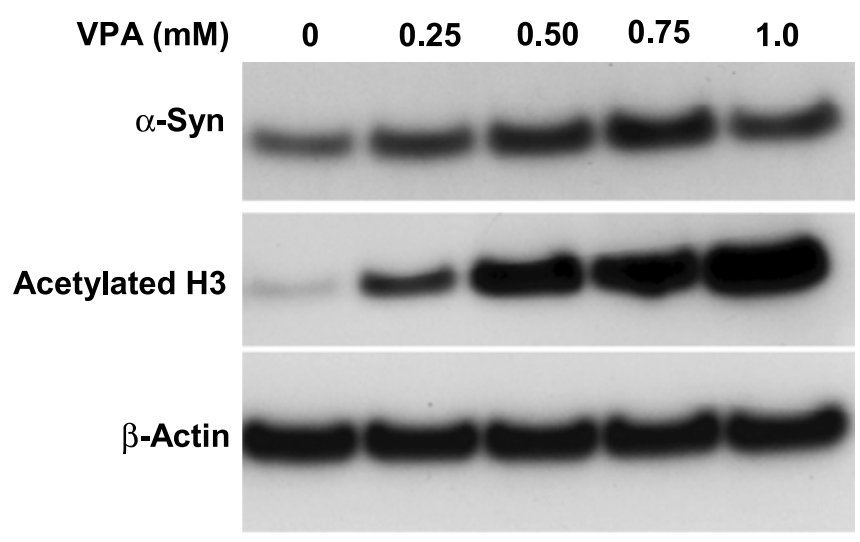

Figure 10. VPA treatment increases levels of $\alpha$-syn and acetylated histone $\mathrm{H} 3$ in rat cortical neuronal cultures. Cerebral cortical neurons were treated with the indicated concentrations of VPA for $4 \mathrm{~d}$, starting from DIV 6. Cells were then harvested for Western blotting of levels of $\alpha$-syn and acetylated histone $\mathrm{H} 3$, using $\beta$-actin as the control.

in CGCs. Bcl-2 has a prominent role in maintaining mitochondrial integrity in the face of reduced mitochondrial membrane potential caused by an apoptotic insult (Vander Heiden and Thompson, 1999). The expression of a number of genes was upregulated by $\alpha$-syn antisense treatment, and these gene products are involved in apoptosis induction, caspase activation, and ubiquitin ligation. The downregulation of Bcl-2 mRNA and upregulation of Ube2n mRNA were confirmed by RT-PCR and realtime PCR analyses. Moreover, $\alpha$-syn antisense oligonucleotides upregulated Ube2n mRNA and downregulated Bcl-2 in the presence of VPA, which by itself increased Bcl-2. Western blotting confirmed $\alpha$-syn antisense-induced upregulation of Ube2n and downregulation of $\mathrm{Bcl}-2$ in the absence and presence of VPA. Ube $2 n$ is a homolog of yeast Ubc13, and its functional role in mammalian neurons is not well understood. However, Ubc13 has been shown to be required for the ubiquitination of TRAF2 (tumor necrosis factor receptor adaptor factor-2) and activation of JNK (Habelhah et al., 2004). JNK activation and JNK down- 
stream activator protein-1 binding have a key role in glutamateinduced excitotoxicity in CGCs (Chen et al., 2003). Ubc13 in conjunction with Ubc variant has also been shown to mediate the assembly of Lys 63-linked polyubiquitin chains (Hofmann and Pickart, 1999). Given that Lys 63-linked chains are involved in diverse functions including neurodegeneration (Doss-Pepe et al., 2005; Lim et al., 2005), $\alpha$-syn-mediated regulation of Ube2n and Bcl-2 may be part of the molecular mechanisms underlying VPAinduced neuroprotection shown in this study.

$\alpha$-Syn has been shown to be a secretable protein found in the CSF of human subjects and culture medium (Borghi et al., 2000; El-Agnaf et al., 2003; Lee et al., 2005; Sung et al., 2005). At present, it is unclear as to whether the neuroprotective effects are mediated by secretion of upregulated $\alpha$-syn to act on the cell surface or are attributable to a direct action of intracellular $\alpha$-syn on cellular machinery. It has been reported that exogenous $\alpha$-syn at relatively low concentrations activates the cell-survival factor Akt and induces the cytoprotective protein $\mathrm{Bcl}-\mathrm{X}_{\mathrm{L}}$ but downregulates the proapoptotic protein Bax in PC12 cells, and these effects are reversed by raising the concentrations of $\alpha$-syn to a toxic level (Seo et al., 2002). In GT-17 cells, $\alpha$-syn transfection also suppresses $\mathrm{H}_{2} \mathrm{O}_{2}$-induced activation of JNK and cell death, and the JNK inactivation is accompanied by increased expression and activity of a JNK-interacting protein JIP, the scaffold protein for the JNK signaling pathway (M. Hashimoto et al., 2002). Consistent with this notion, our preliminary results showed that exogenous $\alpha$-syn protected CGCs from glutamate excitotoxicity, and this neuroprotection was associated with suppression of glutamateinduced phosphorylation (i.e., activation) of JNK (data not shown). The protection against paraquat-induced neurodegeneration in mice overexpressing $\alpha$-syn, either human wild-type or A53T mutant form, is characterized by increased levels of the chaperone protein heat shock protein 70 (HSP70) (Manning-Bog et al., 2003). Moreover, TAT- $\alpha$-syn at nanomolar concentrations is able to increase HSP70 levels, whereas at micromolar scales, TAT- $\alpha$-syn causes a reduction in HSP70 levels (Albani et al., 2004). Our recent study showed that VPA treatment increases HSP70 levels in both brain hemispheres of rats subjected to middle cerebral artery occlusion (Ren et al., 2004). The role of $\alpha$-syn in mediating VPA-induced HSP70 expression requires additional investigation.

It is likely that $\alpha$-syn induction by VPA is mediated through inhibition of HDAC by this drug. This presumption is based on the results that VPA markedly inhibited the activity of HDAC and caused histone $\mathrm{H} 3$ hyperacetylation under our experimental conditions, and that two other HDAC inhibitors, 4-phenylbutyrate and TSA, mimicked the ability of VPA to upregulate $\alpha$-syn and to protect against excitotoxicity. The neuroprotective effects of VPA, phenylbutyrate, and TSA against glutamate neurotoxicity required a minimum of 2-3 d pretreatment (data not shown), reminiscent of our previous results (Kanai et al., 2004). VPA and phenylbutyrate are fatty acid derivatives and predominantly act on class I HDAC, which consists of HDAC1, HDAC2, HDAC3, and HDAC8, whereas TSA is structurally dissimilar and does not exhibit isoenzyme selectivity (Krämer et al., 2003). Moreover, VPA, but not TSA, induces proteasomal degradation of HDAC2. HDAC catalyzes the removal of acetyl groups from lysine residues

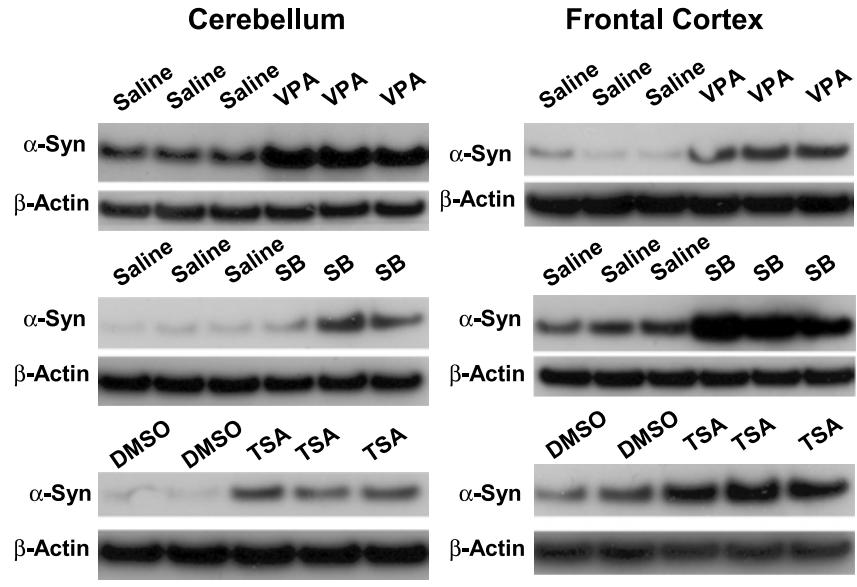

Figure 11. Repeated injections of rats with VPA, sodium butyrate, and TSA increase brain levels of $\alpha$-syn protein. Male Sprague Dawley rats ( $250 \pm 10 \mathrm{~g}$ ) were subjected to daily subcutaneous injections with VPA (300 mg/kg in saline), sodium butyrate (SB) (300 mg/kg in saline), TSA (0.2 mg/kg in DMSO), and their respective vehicle. Four days later, animals were killed by decapitation. The brains were removed and dissected, followed by homogenization and sonication for $40 \mathrm{~s}$ in lysis buffer as described previously (Ren et al. 2004). An aliquot of 15 $\mu \mathrm{g}$ was used for Western blotting as described in Materials and Methods. The blot in each lane represents the result from an individual animal.
B

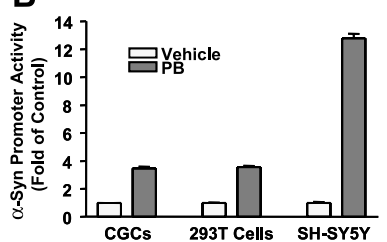

C

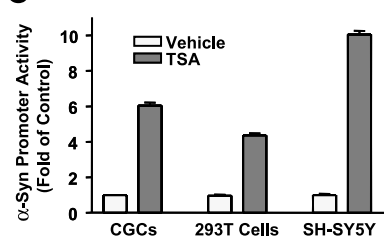

Figure 12. HDAC inhibitors induce a robust increase in the promoter activity of $\alpha$-syn. CGCS, human embryonic kidney 293T means \pm SEM from three independent experiments. Note that treatment with VPA induced a robust increase in the $\alpha$-syn promoter activity in CGCs and HEK 293T cells and an even greater increase in SH-SY5Y cells. Similar increases in $\alpha$-syn promoter activity were observed in all three cell types treated with PB or TSA.
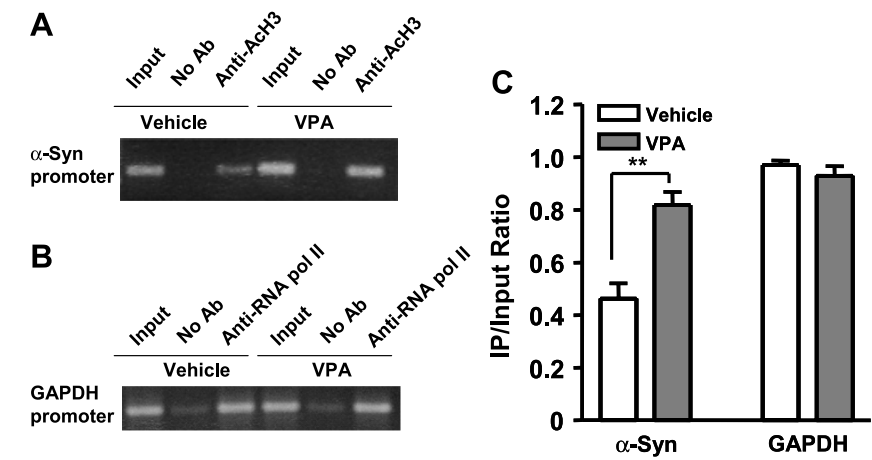

Figure 13. VPA induces hyperacetylation of histone $\mathrm{H} 3$ in the $\alpha$-syn promoter region in neuroblastoma SH-SY5Y cells. SH-SY5Y cells transfected with the pASP-1.9 construct were treated with VPA (1 mm) or vehicle for $24 \mathrm{~h}$ and then cross-linked with $1 \%$ formaldehyde, and the chromatin was prepared and sheared by sonication. The protein/DNA complex was incubated with or without an antibody (No Ab) against acetylated histone H3 for ChIP analysis, and PCR was performed to amplify $\alpha$-syn promoter $(\boldsymbol{A})$. The protein/DNA complex was also incubated with or without antibody against RNA pol II for ChIP analysis and PCR amplification of GAPDH promoter, which served as a positive reagent control $(\boldsymbol{B})$. The quantified data are means \pm SEM of the ratio of relative optical densities of bands within immunoprecipitated (IP) samples and input lanes derived from ethidium bromide-stained gels from four independent experiments (C). ${ }^{* *} p<0.01$ compared with the $\alpha$-syn promoter in cells treated with the vehicle control. 
of histones (Krämer et al., 2003). Accordingly, HDAC inhibition results in increased levels of acetylation in histone tails and enhanced relaxation of chromatin attributable to disruption in the histone-DNA and histone-histone interactions. This chromatin remodeling can result in stimulation and, sometimes, inhibition of gene expression (Kang et al., 2002; Langley et al., 2005). Thus, VPA-induced changes in protein acetylation likely contribute to the promoter activation of $\alpha$-syn genes. This notion is supported by our demonstration of VPA-induced hyperacetylation of histone $\mathrm{H} 3$ in the $\alpha$-syn promoter, as determined by ChIP assay and a robust increase in $\alpha$-syn promoter activity assessed by transfection of the pASP-1.9 construct into neurons treated with VPA and other HDAC inhibitors. Given that HDAC inhibitors were reported to enhance the acetylation level of the cell-survival transcription factor specificity protein-1 (Ryu et al., 2003), we cannot exclude the possibility that VPA-induced hyperacetylation of protein(s) other than histones is also involved in $\alpha$-syn induction and neuroprotection. The effects of HDAC inhibition on $\alpha$-syn expression in vivo were shown in our study in which rats were injected with VPA, SB, and TSA. All three HDAC inhibitors markedly increased $\alpha$-syn protein levels in the cerebellum and frontal cortex after treatment for $4 \mathrm{~d}$, similar to our results derived from CGCs and cortical neurons. An increase in $\alpha$-syn protein was also detected at earlier time points (such as $2 \mathrm{~d}$ ) and lasted for at least $7 \mathrm{~d}$ (data not shown). Under similar treatment conditions, we found that cerebral ischemia-induced brain infarction and neurological deficits were robustly inhibited (Ren et al., 2004; Kim et al., 2005), suggesting a potential role of $\alpha$-syn induction in mediating neuroprotection against ischemiainduced excitotoxicity.

It has been reported that VPA prolongs the lifespan of neuronal cultures (Jeong et al., 2003), activates Akt (De Sarno et al., 2002) and extracellular signal-regulated kinase (Yuan et al., 2001; Hao et al., 2004; Hsieh et al., 2004), stimulates neuronal differentiation (Hsieh et al., 2004), and induces cytoprotective proteins such as Bcl-2 (Chen et al., 1999), glucose-regulated protein 78 (Bown et al., 2000; Kim et al., 2004), brain-derived neurotrophic factor (Fukumoto et al., 2001), and HSP70 (Jeong et al., 2003; Ren et al., 2004). Excitotoxicity induced by excessive glutamate at the synapse has been implicated in the pathogenesis of a growing number of neurodegenerative diseases, including stroke, Huntington's disease, ALS, spinal cord injury, cerebellar degeneration, and possibly Alzheimer's and Parkinson's diseases (for review, Friedlander, 2003). Collectively, the present research suggests that VPA is a potential drug for treating some forms of neurodegenerative diseases, in addition to its common use for seizures and bipolar disorder.

\section{References}

Albani D, Peverelli E, Rametta R, Batelli S, Veschini L, Negro A, Forloni G (2004) Protective effect of TAT-delivered alpha-synuclein: relevance of the C-terminal domain and involvement of HSP70. FASEB J 18:1713-1715.

Alves da Costa CA, Ancolio K, Checler F (2000) Wild-type but not Parkinson's disease-related Ala- $53 \rightarrow$ Thr mutant $\alpha$-synuclein protects neuronal cells from apoptotic stimuli. J Biol Chem 275:24065-24069.

Alves da Costa CA, Paitel E, Vincent B, Checler F (2002) $\alpha$-synuclein lowers p53-dependent apoptotic response of neuronal cells. J Biol Chem 277:50980-50984.

Bantounas I, Phylactou LA, Uney JB (2004) RNA interference and the use of small interfering RNA to study gene function in mammalian systems. J Mol Endocrinol 33:545-557.

Borghi R, Marchese R, Negro A, Marinelli L, Forloni G, Zaccheo D, Abbruzzese G, Tabaton M (2000) Full length alpha-Synuclein is present in cere- brospinal fluid from Parkinson's disease and normal subjects. Neurosci Lett 287:65-67.

Bown CD, Wang JF, Young LT (2000) Increased expression of endoplasmic reticulum stress proteins following chronic valproate treatment of rat C6 glioma cells. Neuropharmacology 39:2162-2169.

Cabin DE, Shimazu K, Murphy D, Cole NB, Gottschalk W, Mcllwain KL, Orrison B, Chen A, Ellis CE, Paylor R, Lu B, Nussbaum RL (2002) Synaptic vesicle depletion correlates with attenuated synaptic responses to prolonged repetitive stimulation in mice lacking $\alpha$-synuclein. J Neurosci 22:8797-8807.

Chandra S, Gallardo G, Fernandez-Chacon R, Schluter OM, Sudhof TC (2005) $\alpha$-Synuclein cooperates with $\operatorname{CSP} \alpha$ in preventing neurodegeneration. Cell 123:383-396.

Chen G, Zeng WZ, Yuan PX, Huang LD, Jiang YM, Zhao ZH, Manji HK (1999) The mood-stabilizing agents lithium and valproate robustly increase the levels of the neuroprotective protein bcl-2 in the CNS. J Neurochem 72:879-882.

Chen RW, Qin ZH, Ren M, Kanai H, Chalecka-Franaszek E, Leeds P, Chuang DM (2003) Regulation of c-Jun N-terminal kinase, p38 kinase and AP-1 DNA binding in cultured brain neurons: roles in glutamate excitotoxicity and lithium neuroprotection. J Neurochem 84:566-575.

Chiba-Falek O, Nussbaum RL (2001) Effect of allelic variation at the NACPRep1 repeat upstream of the alpha-Synuclein gene (SNCA) on transcription in a cell culture luciferase reporter system. Hum Mol Genet 10:3101-3109.

Dawson TM, Dawson VL (2003) Molecular pathways of neurodegeneration in Parkinson's disease. Science 302:819-822.

De Sarno P, Li XH, Richard JS (2002) Regulation of Akt and glycogen synthase kinase- 3 phosphorylation by sodium valproate and lithium. Neuropharmacology 43:1158-1164.

Doss-Pepe EW, Chen L, Madura K (2005) $\alpha$-Synuclein and Parkin contribute to the assembly of ubiquitin lysine 63-linked multiubiquitin chains. J Biol Chem 280:16619-16624.

El-Agnaf OM, Salem SA, Paleologou KE, Cooper LJ, Fullwood NJ, Gibson MJ, Curran MD, Court JA, Mann DM, Ikeda S, Cookson MR, Hardy J, Allsop D (2003) $\alpha$-Synuclein implicated in Parkinson's disease is present in extracellular biological fluids, including human plasma. FASEB J 17:1945-1947.

Friedlander RM (2003) Mechanisms of disease: apoptosis and caspases in neurodegenerative diseases. N Engl J Med 348:1365-1375.

Fukumoto T, Morinobu S, Okamoto Y, Kagaya A, Yamawaki S (2001) Chronic lithium treatment increases the expression of brain-derived neurotrophic factor in the rat brain. Psychopharmacology (Berl) 158:100-106.

Göttlicher M, Minucci S, Zhu P, Krämer OH, Schimpf A, Giavara S, Sleeman JP, Lo Coco F, Nervi C, Pelicci PG, Heinzel T (2001) Valproic acid defines a novel class of HDAC inhibitors inducing differentiation of transformed cells. EMBO J 20:6969-6978.

Habelhah H, Takahashi S, Cho SG, Kadoya T, Watanabe T, Ronai Z (2004) Ubiquitination and translocation of TRAF2 is required for activation of JNK but not of p38 or NF-kappaB. EMBO J 23:322-332.

Hao Y, Creson T, Zhang L, Li P, Du F, Yuan P, Gould TD, Manji HK, Chen G (2004) Mood stabilizer valproate promotes ERK pathway-dependent cortical neuronal growth and neurogenesis. J Neurosci 24:6590-6599.

Hashimoto M, Hsu LJ, Rockenstein E, Takenouchi T, Mallory M, Masliah E (2002) $\alpha$-Synuclein protects against oxidative stress via inactivation of the c-Jun N-terminal kinase stress-signaling pathway in neuronal cells. J Biol Chem 277:11465-11472.

Hashimoto R, Hough C, Nakazawa T, Yamamoto T, Chuang DM (2002) Lithium protection against glutamate excitotoxicity in rat cerebral cortical neurons: involvement of NMDA receptor inhibition possibly by decreasing NR2B tyrosine phosphorylation. J Neurochem 80:589-597.

Hiroi T, Wei H, Hough C, Leeds P, Chuang DM (2005) Protracted lithium treatment protects against the ER stress elicited by thapsigargin in rat PC12 cells: roles of intracellular calcium, GRP78 and Bcl-2. Pharmacogenomics J 5:102-111.

Hofmann RM, Pickart CM (1999) Noncanonical MMS2-encoded ubiquitinconjugating enzyme functions in assembly of novel polyubiquitin chains for DNA repair. Cell 96:645-653.

Hsieh J, Nakashima K, Kuwabara T, Mejia E, Gage FH (2004) Histone deacetylase inhibition-mediated neuronal differentiation of multipotent adult neural progenitor cells. Proc Natl Acad Sci USA 101:16659-16664. Jensen PJ, Alter BJ, O’Malley KL (2003) $\alpha$-Synuclein protects naive but 
not dbcAMP-treated dopaminergic cell types from 1-methyl-4phenylpyridinium toxicity. J Neurochem 86:196-209.

Jeong MR, Hashimoto R, Senatorov VV, Fujimaki K, Ren M, Lee MS, Chuang DM (2003) Valproic acid, a mood stabilizer and anticonvulsant, protects rat cerebral cortical neurons from spontaneous cell death: a role of histone deacetylase inhibition. FEBS Lett 542:74-78.

Jo EJ, McLaurin JA, Yip CM, George-Hyslop PS, Fraser PE (2000) $\alpha$-Synuclein membrane interactions and lipid specificity. J Biol Chem 275:34328-34334.

Kanai H, Sawa A, Chen RW, Leeds P, Chuang DM (2004) Valproic acid inhibits histone deacetylase activity and suppresses excitotoxicityinduced GAPDH nuclear accumulation and apoptotic death in neurons. Pharmacogenomics J 4:336-344.

Kang HL, Benzer S, Min KT (2002) Life extension in Drosophila by feeding a drug. Proc Natl Acad Sci USA 99:838-843.

Kawamata H, McLean PJ, Sharma N, Hyman BT (2001) Interaction of $\alpha$-synuclein and synphilin-1: effect of Parkinson's disease-associated mutations. J Neurochem 77:929-934.

Kim AJ, Shi Y, Austin RC, Werstuck GH (2004) Valproate protects cells from ER stress-induced lipid accumulation and apoptosis by inhibiting glycogen synthase kinase-3. J Cell Sci 118:89-99.

Kim HJ, Ren M, Hong JS, Chuang DM (2005) Postinsult treatment with valproate or sodium butyrate is neuroprotective in the rat PMCAO model: a role of microglia suppression. Soc Neurosci Abstr 31:589.2.

Kohno R, Sawada H, Kawamoto Y, Uemura K, Shibasaki H, Shimohama S (2004) BDNF is induced by wild-type $\alpha$-synuclein but not by the two mutants, A30P or A53T, in glioma cell line. Biochem Biophys Res Commun 318:113-118.

Krämer OH, Zhu P, Ostendorff HP, Golebiewski M, Tiefenbach J, Peters MA, Brill B, Groner B, Bach I, Heinzel T, Göttlicher M (2003) The histone deacetylase inhibitor valproic acid selectively induces proteasomal degradation of HDAC2. EMBO J 22:3411-3420.

Krüger R, Kuhn W, Müller W, Woitalla, Graeber DM, Kösel S, Przuntek H, Epplen JT, Schols L, Riess O (1998) Ala30Pro mutation in the gene encoding $\alpha$-synuclein in Parkinson's disease. Nat Genet 18:106-108.

Langley B, Gensert JM, Beal MF, Ratan RR (2005) Remodeling chromatin and stress resistance in the central nervous system: histone deacetylase inhibitors as novel and broadly effective neuroprotective agents. Curr Drug Targets CNS Neurol Disord 4:41-50.

Lee HJ, Patel S, Lee SJ (2005) Intravesicular localization and exocytosis of $\alpha$-synuclein and its aggregates. J Neurosci 25:6016-6024.

Leng Y, Chase TN, Bennett MC (2001) Muscarinic receptor stimulation induces translocation of an $\alpha$-synuclein oligomer from plasma membrane to a light vesicle fraction in cytoplasm. J Biol Chem 276:28212-28218.

Lim KL, Chew KC, Tan JM, Wang C, Chung KK, Zhang Y, Tanaka Y, Smith W, Engelender S, Ross CA, Dawson VL, Dawson TM (2005) Parkin mediates nonclassical, proteasomal-independent ubiquitination of synphilin-1: implications for Lewy body formation. J Neurosci 25:2002-2009.

Liu S, Ninan I, Antonova I, Battaglia F, Trinchese F, Narasanna A, Kolodilov N, Dauer W, Hawkins RD, Arancio O (2004) $\alpha$-Synuclein produces a long-lasting increase in neurotransmitter release. EMBO J 23:4506-4516.

Manche L, Green SR, Schmedt C, Mathews MB (1992) Interactions between double-stranded RNA regulators and the protein kinase DAI. Mol Cell Biol 12:5238-5248.

Manning-Bog AB, McCormack AL, Purisai MG, Bolin LM, Di Monte DA
(2003) $\alpha$-Synuclein overexpression protects against paraquat-induced neurodegeneration. J Neurosci 23:3095-3099.

McEloroy SL, Keck Jr PE (1995) Antiepileptic drugs. In: Textbook of psychopharmacology (Schatzberg AF, Nemeroff CB, eds), pp 351-375. Washington, DC: American Psychiatric Publishing.

Nonaka S, Hough CJ, Chuang DM (1998) Chronic lithium treatment robustly protects neurons in the central nervous system against excitotoxicity by inhibiting $N$-methyl-D-aspartate receptor-mediated calcium influx. Proc Natl Acad Sci USA 95:2642-2647.

Norris EH, Giasson BI, Lee VM (2004) $\alpha$-Synuclein: normal function and role in neurodegenerative diseases. Curr Top Dev Biol 60:17-54.

Ostrerova N, Petrucelli L, Farrer M, Mehta N, Choi P, Hardy J, Wolozin B (1999) $\alpha$-Synuclein shares physical and functional homology with 143-3 proteins. J Neurosci 19:5782-5791.

Peng GS, Li G, Tzeng NS, Chen PS, Chuang DM, Hsu YD, Yang S, Hong JS (2005) Valproate pretreatment protects dopaminergic neurons from LPS-induced neurotoxicity in rat primary midbrain cultures: role of microglia. Mol Brain Res 134:162-169.

Phiel CJ, Zhang F, Huang EY, Guenther MG, Lazar MA, Klein PS (2001) Histone deacetylase is a direct target of valproic acid, a potent anticonvulsant, mood stabilizer, and teratogen. J Biol Chem 276:36734-36741.

Polymeropoulos MH, Lavedan C, Leroy E, Ide SE, Dehejia A, Dutra A, Pike B, Root H, Rubenstein J, Boyer R, Stenroos ES, Chandrasekharappa S, Athanassiadou A, Papapetropoulos T, Johnson WG, Lazzarini AM, Duvoisin RC, Di Iorio G, Golbe LI, Nussbaum RL (1997) Mutation in the $\alpha$-synuclein gene identified in families with Parkinson's disease. Science 276:2045-2047.

Ren M, Leng Y, Jeong M, Leeds PR, Chuang DM (2004) Valproic acid reduces brain damage induced by transient focal cerebral ischemia in rats: potential roles of histone deacetylase inhibition and heat shock protein induction. J Neurochem 89:1358-1367.

Ryu H, Lee J, Olofsson BA, Mwidau A, Dedeoglu A, Escudero M, Flemington E, Azizkhan-Clifford J, Ferrante RJ, Ratan RR (2003) Histone deacetylase inhibitors prevent oxidative neuronal death independent of expanded polyglutamine repeats via an Sp1-dependent pathway. Proc Natl Acad Sci USA 100:4281-4286.

Seo JH, Rah JC, Choi SH, Shin JK, Min K, Kim HS, Park CH, Kim S, Kim EM, Lee SH, Lee S, Suh SW, Suh YH (2002) $\alpha$-Synuclein regulates neuronal survival via Bcl-2 family expression and PI3/Akt kinase pathway. FASEB J 16:1826-1828.

Simsek-Duran F, Linden DJ, Lonart G (2004) Adapter protein 14-3-3 is required for a presynaptic form of LTP in the cerebellum. Nat Neurosci 7:1296-1298.

Sung JY, Park SM, Lee CH, Um JW, Lee HJ, Kim J, Oh YJ, Lee ST, Paik SR, Chung KC (2005) Proteolytic cleavage of extracellular secreted $\alpha$-synuclein via matrix metalloproteinases. J Biol Chem 280:25216-25224.

Vander Heiden MG, Thompson CB (1999) Bcl-2 proteins: regulators of apoptosis or of mitochondrial homeostasis? Nat Cell Biol 1:E209-E216.

Yuan PX, Huang LD, Jiang YM, Gutkind JS, Manji HK, Chen G (2001) The mood stabilizer valproic acid activates mitogen-activated protein kinases and promotes neurite growth. J Biol Chem 276:31674-31683.

Zarranz JJ, Alegre J, Gomez-Esteban JC, Lezcano E, Ros R, Ampuero I, Vidal L, Hoenicka J, Rodriguez O, Atares B, Llorens V, Gomez Tortosa E, del Ser T, Munoz DG, de Yebenes JG (2004) The new mutation, E46K, of $\alpha$-synuclein causes Parkinson and Lewy body dementia. Ann Neurol 55: 164-173. 